\title{
Atrial Septal Defect: Step-by-Step Catheter Closure
}

\author{
Shreepal A. Jain, $M D^{1}$, Bharat V. Dalvi, MD²* \\ 1 Department of Pediatric Cardiac Sciences, Sir H N Reliance Foundation Hospital, Mumbai, Maharashtra, India \\ ${ }^{2}$ Department of Cardiology, Glenmark Cardiac Center, Mumbai, Maharashtra, India
}

\begin{abstract}
Transcatheter device closure of ASD has come a long way since the first experimental closure in dogs by Kings and Mills in 1972. However, unlike earlier devices, the current generation is easier to deploy and retrieve. The secret to a successful procedure includes meticulous planning and execution. It involves comprehensive evaluation from the point of appropriate case selection, detailed pre- and intra-procedural imaging, knowledge of various techniques of device deployment, and anticipating complications and ways to deal with them. In this paper, we describe the step-bystep procedure for transcatheter closure of an atrial septal defect using the Amplatzer Septal Occluder.

Copyright @ 2016 Science International Corp.
\end{abstract}

\section{Key Words}

Atrial Septal defect - Amplatzer Septal Occluder Catheter closure - Balloon assisted technique • Pulmonary vein deployment technique

\section{Slide Descriptions}

Slide \# 1:

Title slide

Slide \# 10:

Typical electrocardiogram findings [4]:

1. Right axis deviation

2. Incomplete right bundle branch block ( $r s R^{\prime}$ in V1)

3. Right atrial and ventricular enlargement

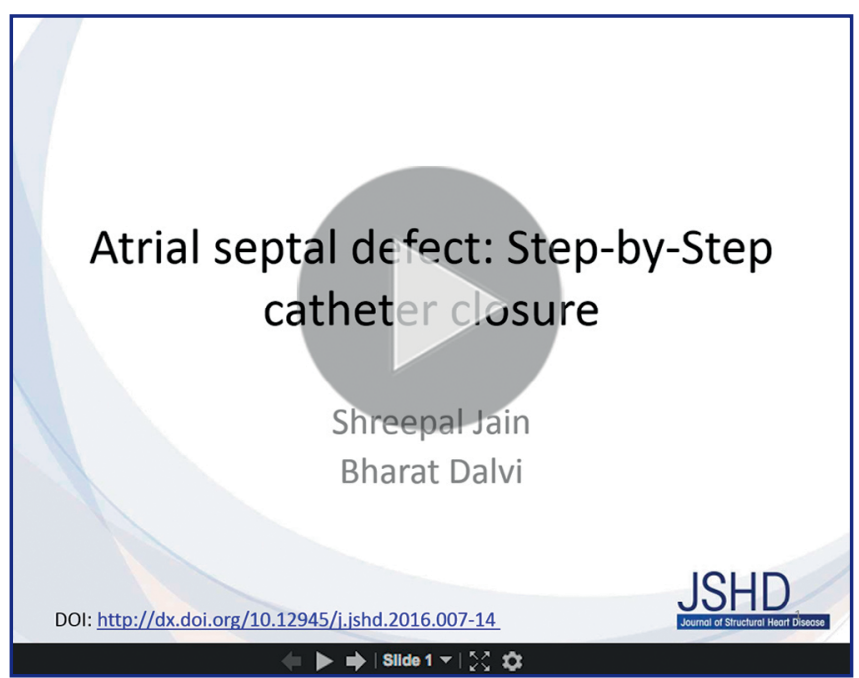

Slideshow. Click on the presentation above to view the presentation online. Please be aware that the presentation has many embedded videos so there is a long load time (90.4MB). You may download the file at http://dx.doi.org/10.12945/j. jshd.2016.007.14.ppt.01.

Slide \# 11:

Chest radiogram findings [4]:

1. Cardiomegaly due to right heart dilatation

2. Dilated main pulmonary artery

3. Pulmonary plethora

Slide \# 13:

The device size is chosen based on the largest dimension recorded in any of the standard views (details in subsequent slides).

* Corresponding Author:

Bharat V. Dalvi, MD

Glenmark Cardiac Center

Department of Cardiology

First Floor, Flat No.101\&102, Opp. Swami Samarth Math \& Dhanwantari Hospital

D L Vaidya Road, Behind Shivsena Bhavan, Dadar (West), Mumbai, Maharashtra 400028

Tel. +91 98 21210188, Fax: +91 22 24335058, E-Mail: bharatdalvi@hotmail.com 


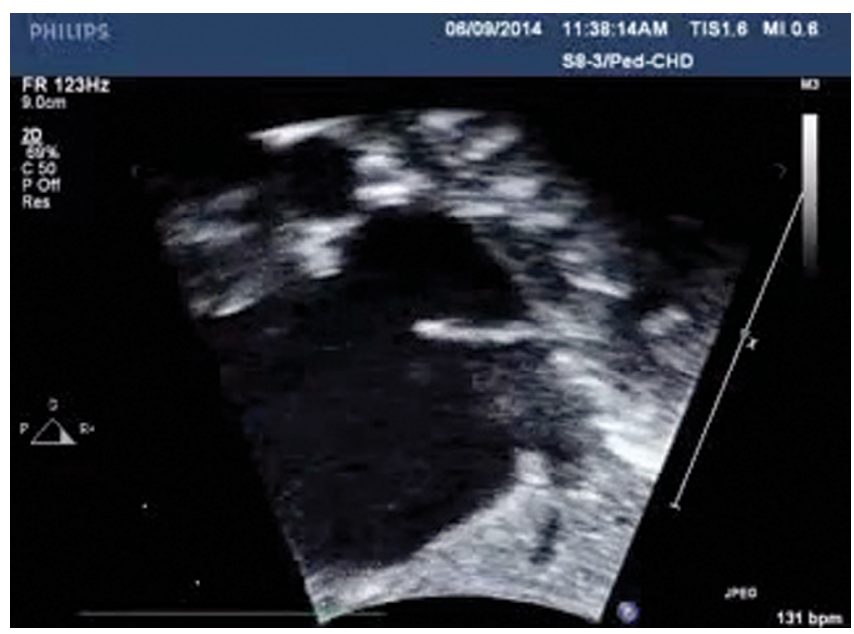

Video 1. Subcostal bicaval view, documenting adequacy of superior vena caval (SVC) and inferior vena caval (IVC) margins. View supplementary video at http://dx.doi.org/10.12945/j. jshd.2016.007.14.vid.01

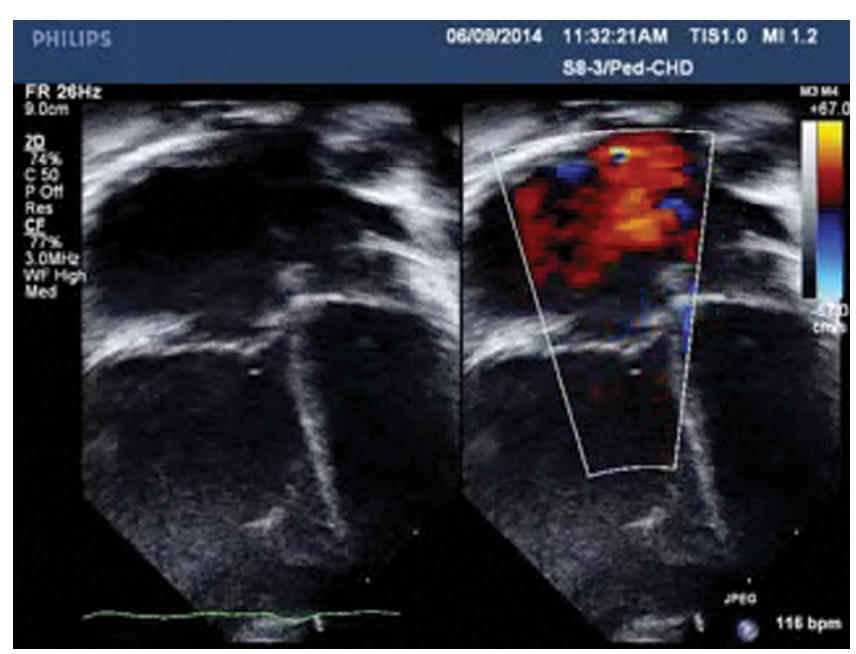

Video 2. Skewed Apical 4 chamber view with color compare showing the atrio-ventricular (or mitral) margin and the posterior margin. View supplementary video at http://dx.doi.org/10.12945/j. jshd.2016.007.14.vid.02.

\section{Slide \# 14:}

Left frame: Subcostal bicaval view, documenting adequacy of superior vena caval (SVC) and inferior vena caval (IVC) margins (Video 1).

Right frame: Skewed Apical 4 chamber view with color compare showing the atrioventricular (or mitral) margin and the posterior margin (Video 2).

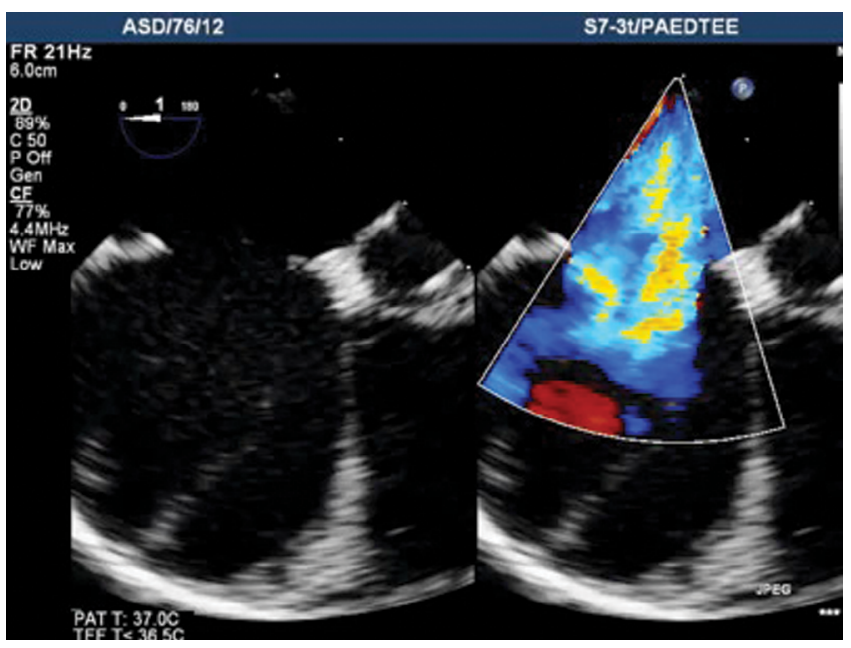

Video 3. TEE at 0 degrees (4-chamber view), showing the AV valve (or mitral) and the posterior margins. View supplementary video at http://dx.doi.org/10.12945/j.jshd.2016.007.14.vid.03.

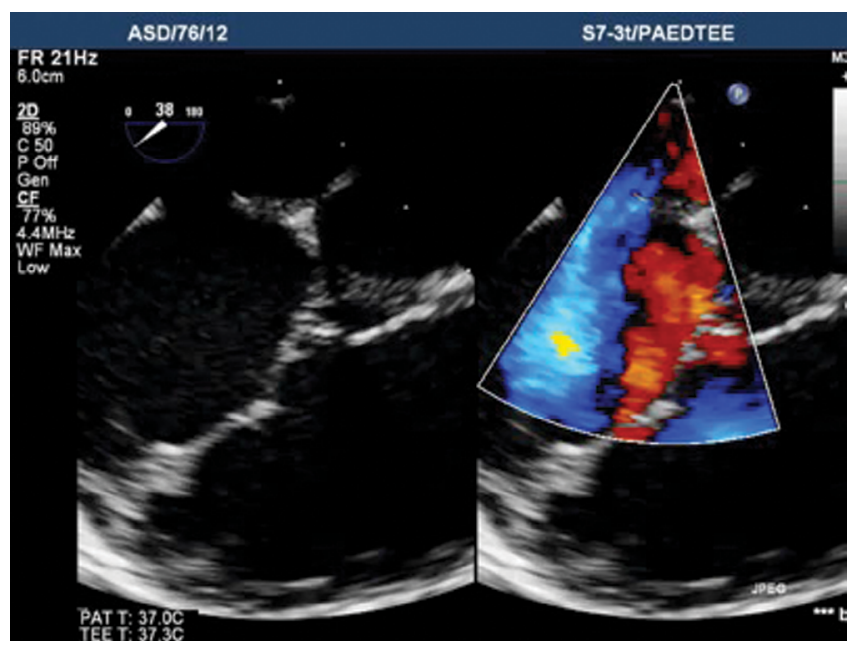

Video 4. TEE at 40 degrees (aortic short axis view), depicting the retroaortic and the posterior margins. View supplementary video at http://dx.doi.org/10.12945/j.jshd.2016.007.14.vid.04.

Slide \# 16:

TEE imaging in different views to confirm adequacy of surrounding margins for device closure of the ASD.

Top left: TEE at 0 degrees (4-chamber view), showing the AV valve (or mitral) and the postero-inferior margins (Video 3). 


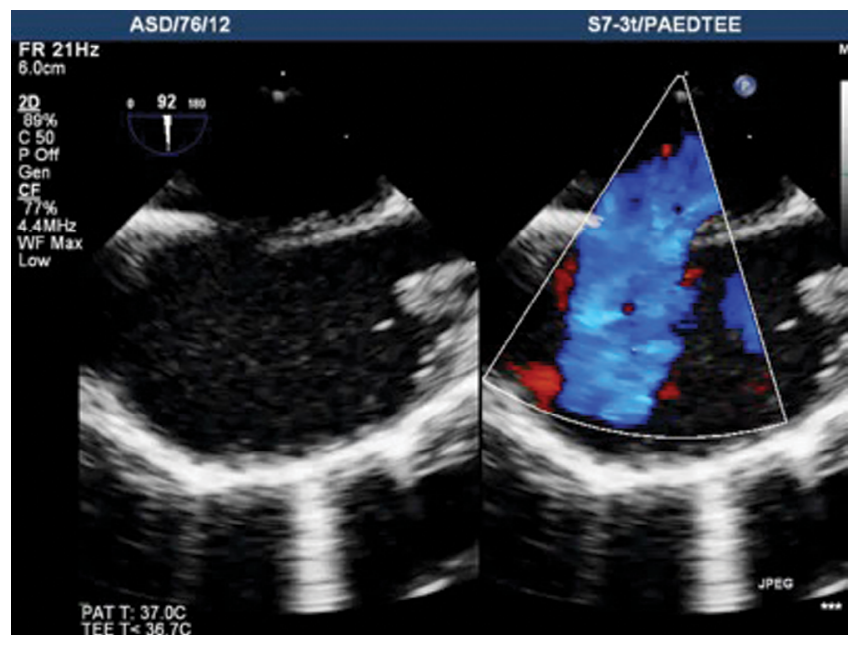

Video 5. TEE at 90 degrees (bicaval view) demonstrates the superior vena caval and inferior vena caval margins. View supplementary video at http://dx.doi.org/10.12945/j.jshd.2016.007.14.
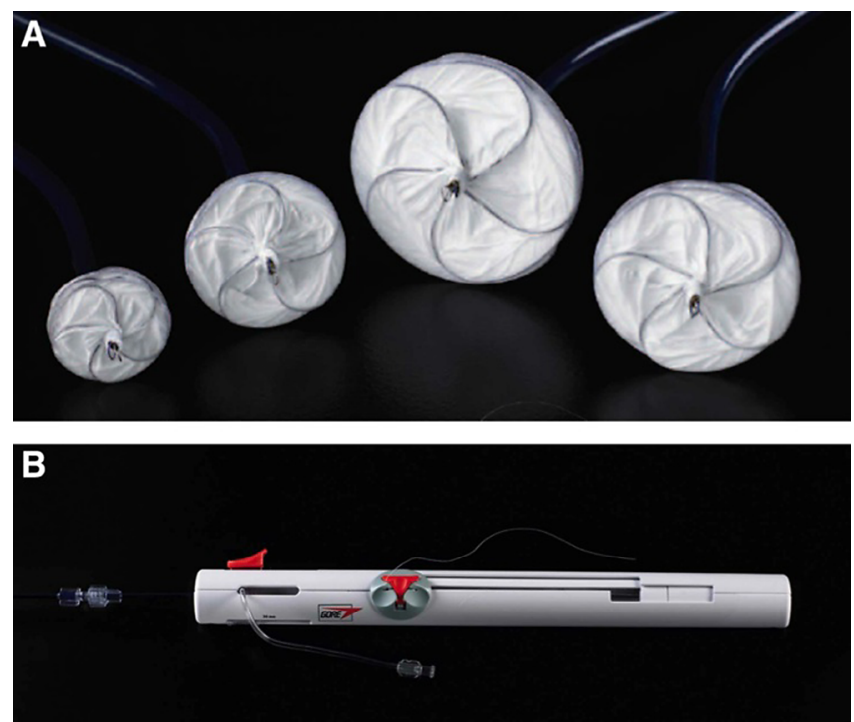

Figure 1. Panel A. When fully deployed, the occluder assumes a double disc configuration that bridges the septal defect to prevent shunting of blood between the right and left atria. Panel B. Device release is a two staged process, firstly locking of the device by the lock loop and then removal of the retrieval cord.

Top right: TEE at 40 degrees (aortic short axis view), depicting the retroaortic and the postero-superior margins (Video 4).

Bottom: TEE at 90 degrees (bicaval view) demonstrates the superior vena caval and inferior vena caval margins (Video 5).
Slide \# 19:

ICE: Intracardiac echocardiography

TTE: Transthoracic echocardiography

TEE: Transesophageal echocardiography

Slide \# 25:

Stop-flow technique: The sizing balloon is placed across the ASD and inflated until there is stoppage of flow across the defect on color-flow Doppler imaging. The maximum width of the balloon is then measured on TTE/TEE/ICE as well as fluoroscopy.

Waist measurement technique: The sizing balloon is placed across the ASD and inflated until there is a waist formation noted along both the margins of the balloon on fluoroscopy. This waist is then measured on fluoroscopy.

Slide \# 26:

The HELEX ${ }^{R}$ Septal Occluder (W.L: Gore \& Associates, Flagstaff, Arizona, USA) is a soft and compliant, non-self-centering device made from a single-length nitinol wire shaped into the left and right atrial discs covered by a polytetraflouroethylene (ePTFE) membrane. The membrane is treated with a hydrophilic coating to facilitate echocardiographic imaging of the occluder during implantation. When fully deployed, the occluder assumes a double disc configuration that bridges the septal defect to prevent shunting of blood between the right and left atria (Figure 1: Panel A). The HELEX ${ }^{R}$ Septal Occluder received FDA clearance in 2006. The HELEX ${ }^{R}$ Septal Occluder, a new device, is the result of an extended development and improvement of the HELEX ${ }^{R}$ Septal Occluder. The wire frame is formed from five wires shaped into the right and left atrial discs, the eyelets, and the lock loop. The five-wire design provides conformability, allowing each individual wire within a right or left atrial disc to conform to the heart anatomy. Device release is a two staged process, firstly locking of the device by the lock loop and then removal of the retrieval cord (Figure 1: Panel B). A 2:1 ratio between the device size and the defect size "balloon-stretched diameter" is used for optimal results, and the device diameter should not exceed $90 \%$ of the measured septal length. The device is available in sizes of $15,20,25,30$, and $35 \mathrm{~mm}$. 


\section{Advantages:}

1. No reported incidence of device erosion or cardiac perforation.

2. Even after locking the device in position after optimal position is confirmed, it can still be retrieved with the help of retrieval cord attached to the right atrial disc.

3. The HELEX ${ }^{R}$ Septal Occluder is a non-self-centering device having a narrow mid portion that makes it suitable for closure of multifenestrated defects.

4. The device can easily be seen on fluoroscopy and echocardiography.

\section{Disadvantages:}

1. Defects larger than $18 \mathrm{~mm}$ cannot be closed with this device.

2. Wire frame fracture has been reported with the HELEX $^{\mathrm{R}}$ Septal Occluder, especially the larger sizes, occurring in 6.4-8.0\% after 1 year [12].

3. In a United States multicentre study of the HELEX $^{R}$ Septal Occluder, used in 143 patients for closure of ASDs, there was a rate of residual leaks of $25.7 \%$ at 12 months [13].

4. There is a fixed right angle between the tip of the delivery catheter and the device. In some cases, especially in children, this distorts the anatomy and orientation of the atrial septum, making it difficult to decide whether the occluder position is optimal. With release of the device there is a pronounced repositioning when the force from the delivery system is taken away from the septum.

\section{Slide \# 27:}

The Occlutech Figulla Flex II (Occlutech $\mathrm{GmbH}$, Jena, Germany) is a self-expanding nitinol wire mesh, very similar to the Amplatzer device in shape, but with a different design that eliminates the left atrial microscrew (left figure). The device, developed using a unique patented braiding technique, consists of a nitinol wire mesh to create a smooth and flexible outer layer. Two retention discs allow for a single central pin on the right atrial side. Two polyethylene terephthalate (PET) patches assure complete closure after implantation. Available sizes range between 4 to $40 \mathrm{mms}$.

\section{Advantages:}

1. There is a $50 \%$ reduction of meshwork material on the left atrial side along with elimination of the left atrial disc microsrew, minimizing both the risk of thrombus formation and damage to the distal wall of the left atrium during implantation.

2. The delivery cable mechanism is different and allows pivoting of the device (up to $50^{\circ}$ ), which facilitates positioning across the septum; an advantageous feature especially in large defects and borderline length of rims (right figure).

3. The device is fully recapturable and repositionable.

Slide \# 28:

The Amplatzer Septal Occluder device (St. Jude, Plymouth, Minnesota, USA) is a self-expandable double-disk device made of a nitinol (55\% nickel; $45 \%$ titanium) wire mesh. The ASO device is constructed from a $0.004-0.0075$-inch nitinol wire mesh that is tightly woven into two flat disks. There is a 3-4-mm connecting waist between the two disks, corresponding to the thickness of the atrial septum.

\section{Slide \# 29:}

*This will be in context of Amplatzer Septal Occluder (St. Jude, Plymouth, Minnesota, USA).

Slide \# 30:

These sheath sizes are recommended by the manufacturer depending on the size of the device. Our practice is to use a sheath $1 \mathrm{Fr}$ larger than the recommended size excepting in children weighing less than $15 \mathrm{~kg}$ in whom we use the same size as per the recommendations.

${ }^{*} \mathrm{~A} 40-\mathrm{mm}$ device is not available in the US.

\section{Slide \# 31:}

A. Loader - used to introduce the Amplatzer Septal Occluder into the delivery sheath.

B. Hemostatic valve with extension tube and stopcock - allows flushing the delivery system and controls back-bleeding.

C. Delivery sheath - provides a pathway through which a device is delivered. 


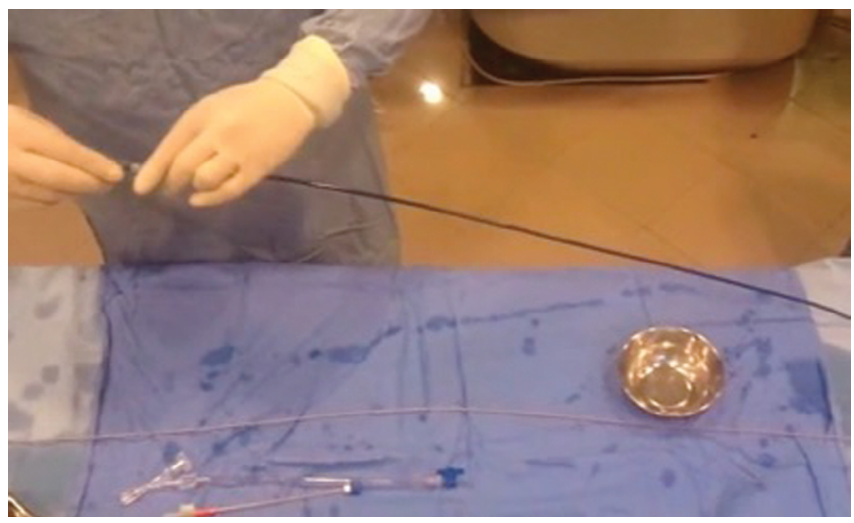

Video 6. All the components of the delivery system are thoroughly flushed and wiped from outside with heparinized saline solution. View supplementary video at http://dx.doi. org/10.12945/j.jshd.2016.007.14.vid.06.

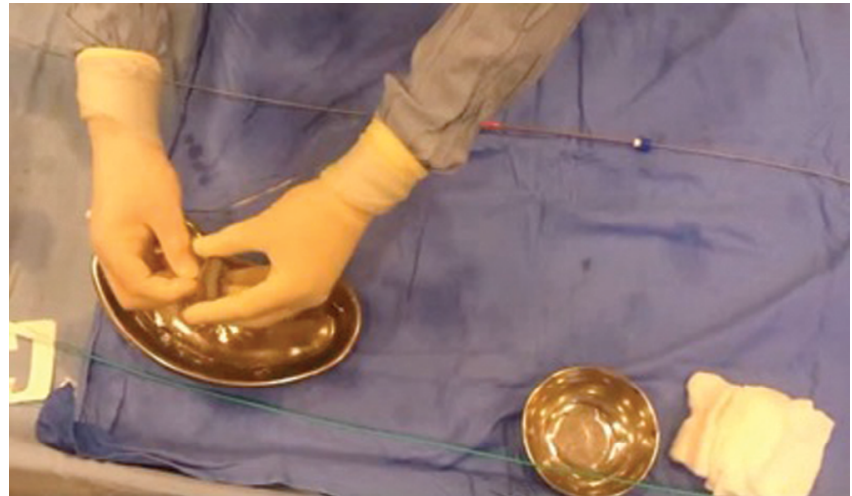

Video 7. It is necessary to load the device after gently messaging it in heparinized saline so as to get rid of the air that might have been trapped in the Dacron patches. It is always a good habit to double check that the device is screwed onto the cable securely. View supplementary video at http://dx.doi.org/10.12945/j. jshd.2016.007.14.vid.07.

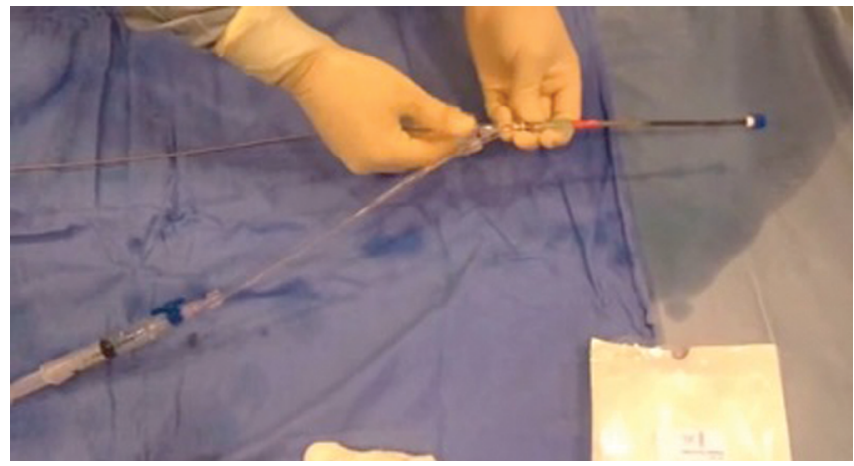

Video 8. The ASO is slenderized within the loader followed by thorough flushing to get rid of the air within the system. View supplementary video at http://dx.doi.org/10.12945/j. jshd.2016.007.14. vid.08.

Jain, S. et al.

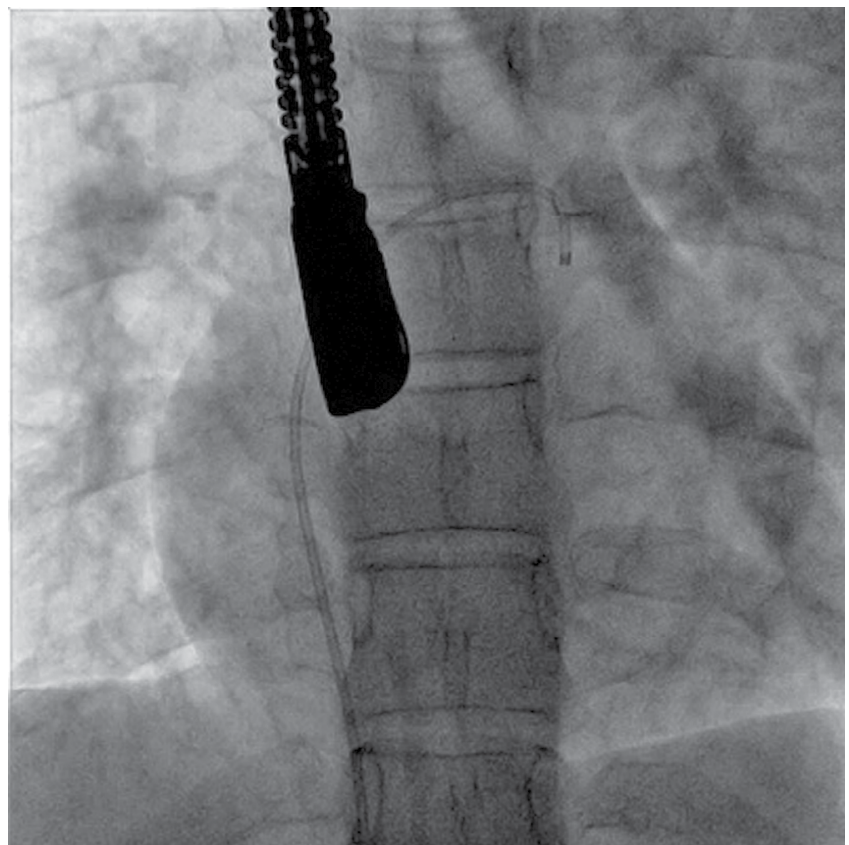

Video 9. Crossing the defect with a Judkin's right coronary artery catheter. The catheter tip is positioned in the left superior pulmonary vein (LSPV). View supplementary video at http:// dx.doi.org/10.12945/j.jshd.2016.007.14.vid.09

D. Dilator - used to ease penetration of skin and the subcutaneous tissue.

E. Delivery cable - the device is screwed onto the distal tip of the delivery cable, which allows for placement (and if necessary, retrieval) of the device.

F. Plastic vise - attached to the delivery cable, serving as a "handle" for detaching (unscrewing) the delivery cable from the device.

Slide \# 32:

All the components of the delivery system are thoroughly flushed and wiped from outside with heparinized saline solution (Video 6).

\section{Slide \# 33:}

It is necessary to load the device after gently messaging it in heparinized saline so as to get rid of the air that might have been trapped in the Dacron patches. It is always a good habit to double check that the device is screwed onto the cable securely (Video 7). 


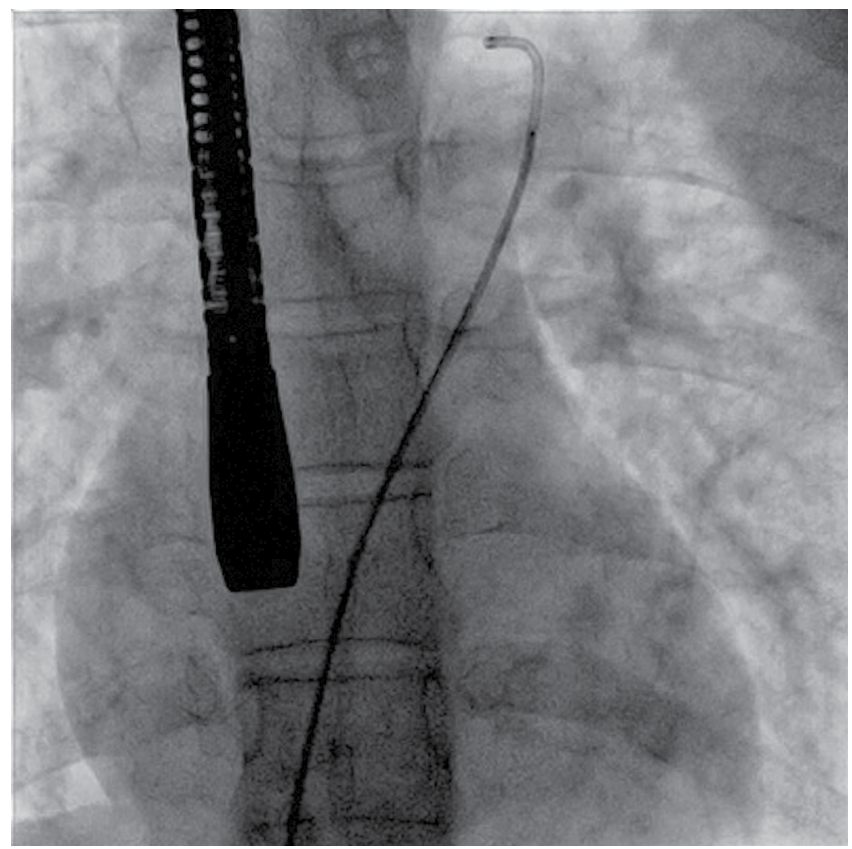

Video 10. A floppy tip Amplatz Superstiff'm guide wire (Boston Scientific, Marlborough, Massachusetts, USA) being placed in the LSPV. View supplementary video at http://dx.doi. org/10.12945/j.jshd.2016.007.14.vid.10.

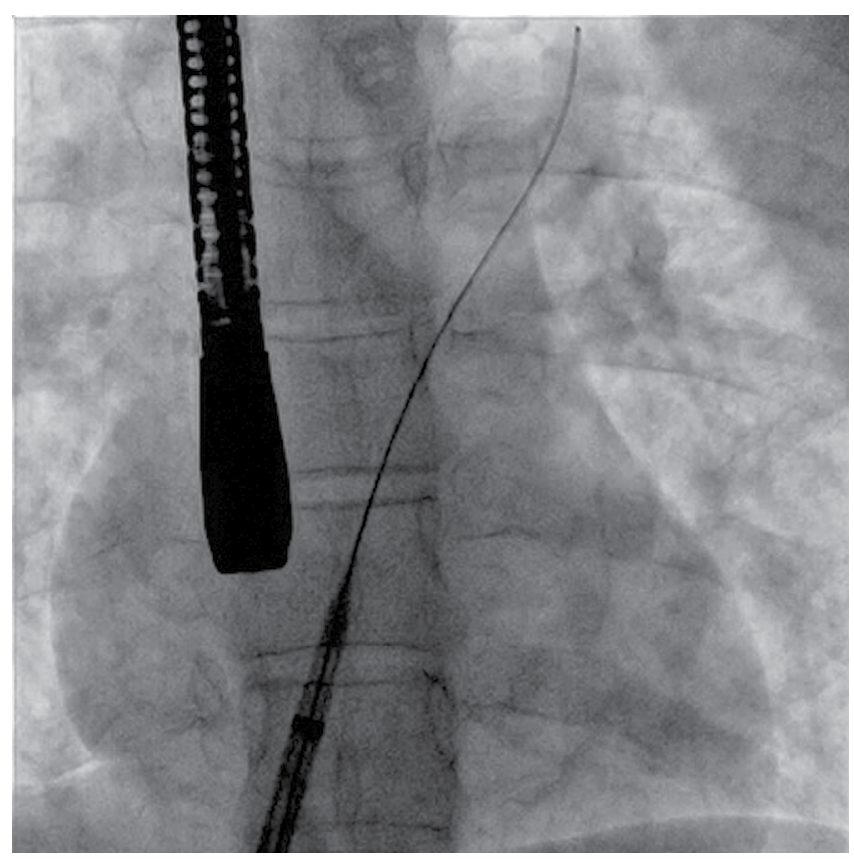

Video 11. An Amplatzer TorqVue ${ }^{T M} 45^{\circ}$ delivery sheath (St. Jude, Plymouth, MN, USA) being passed over the Superstiff wire into the mouth of the LSPV. View supplementary video at http:// dx.doi.org/10.12945/j.jshd.2016.007.14.vid.11.

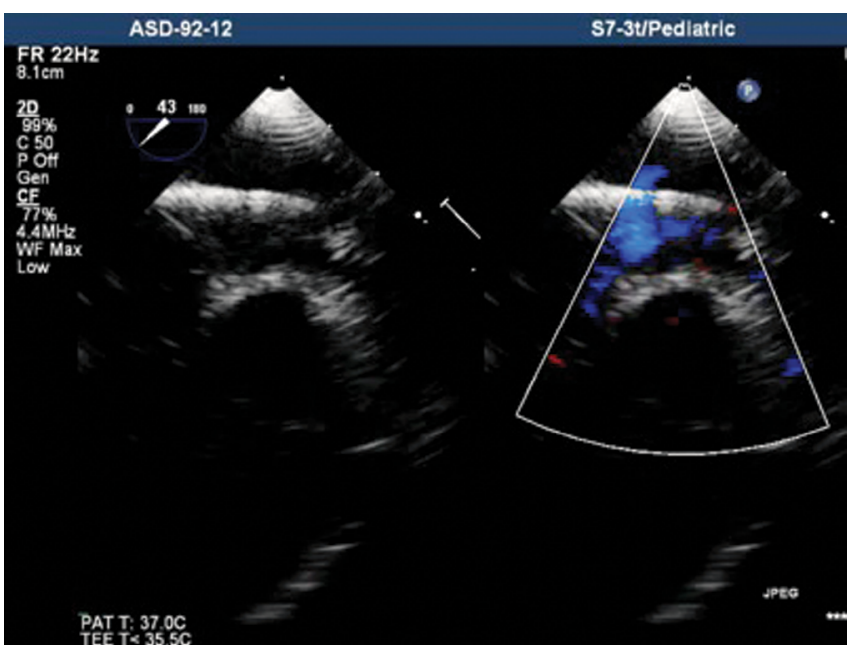

Video 12. Corresponding TEE loop depicting the delivery sheath positioned in the LSPV. View supplementary video at http://dx.doi.org/10.12945/j.jshd.2016.007.14.vid.12.

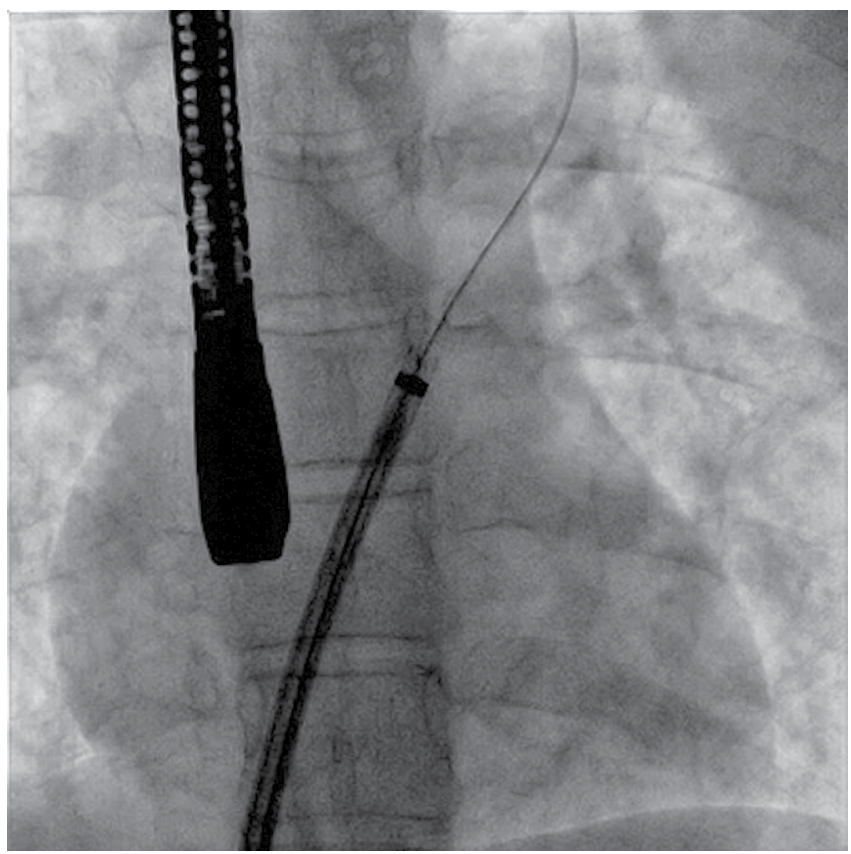

Video 13. Delivery sheath is being advanced over the dilator into the mouth of LSPV. View supplementary video at http://dx. doi.org/10.12945/j.jshd.2016.007.14.vid.13.

Slide \# 34:

The ASO being slenderized within the loader followed by thorough flushing to get rid of the air within the system (Video 8). 


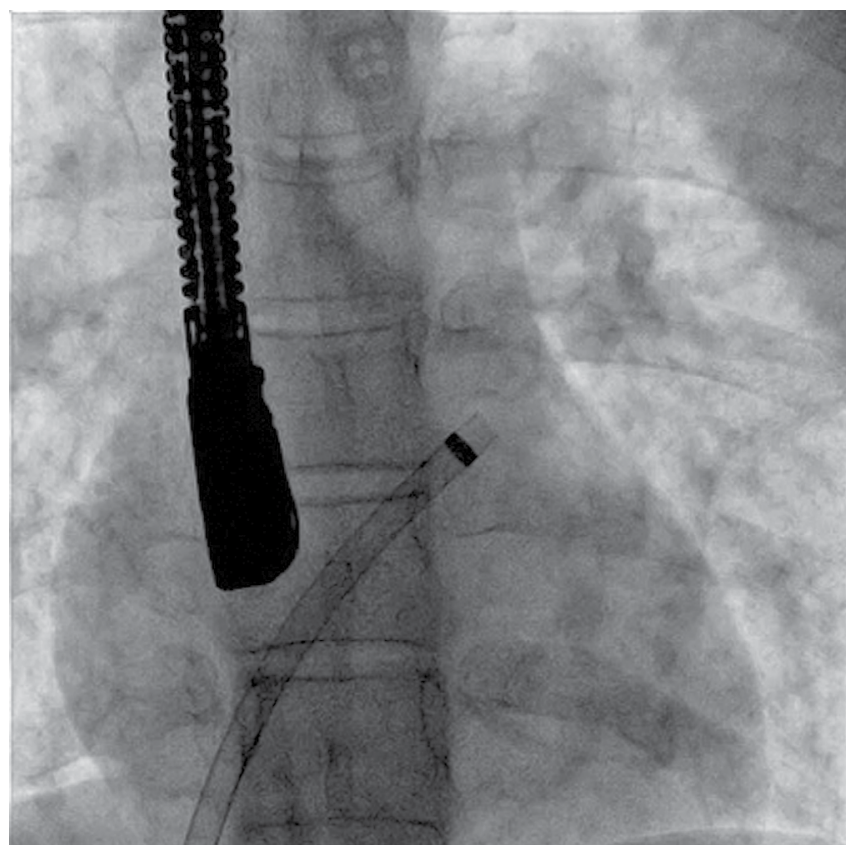

Video 14. The delivery sheath positioned in the left atrium just outside the LSPV. View supplementary video at http://dx.doi. org/10.12945/j.jshd.2016.007.14.vid.14.

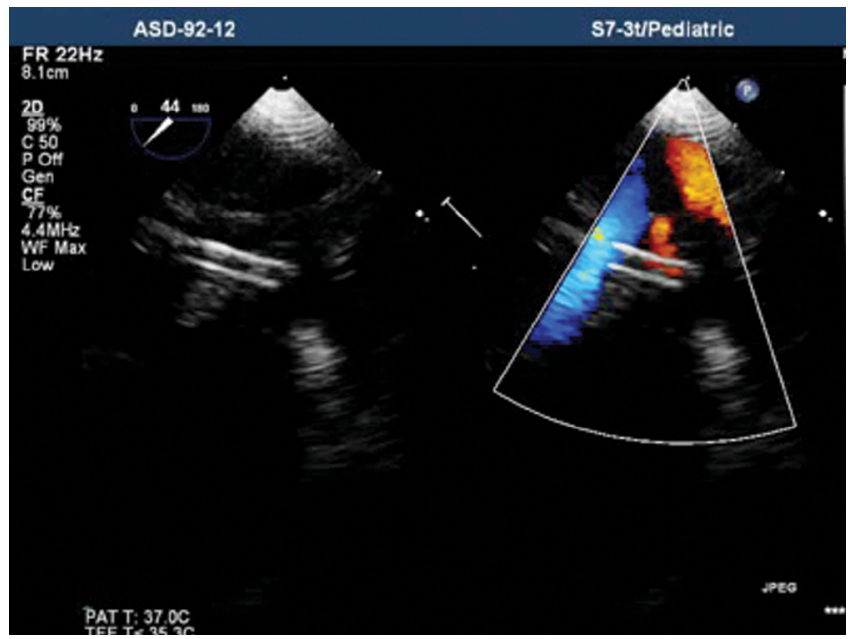

Video 15. Corresponding TEE loop showing the sheath in the left atrium near the opening of the LSPV. View supplementary video at http://dx.doi.org/10.12945/j.jshd.2016.007.14.vid.15.

\section{Slide \# 35:}

Left frame: Crossing the defect with a Judkin's right coronary artery catheter. The catheter tip is positioned in the left superior pulmonary vein (LSPV) (Video 9).

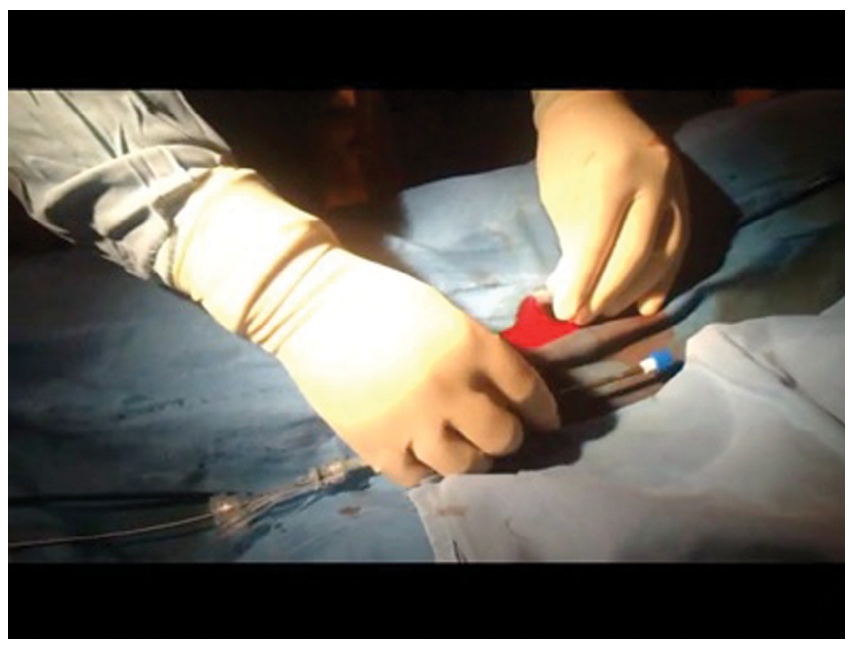

Video 16. Dilator is removed from the sheath to allow back bleed and prevent air embolism. View supplementary video at http://dx.doi.org/10.12945/j.jshd.2016.007.14.vid.16.

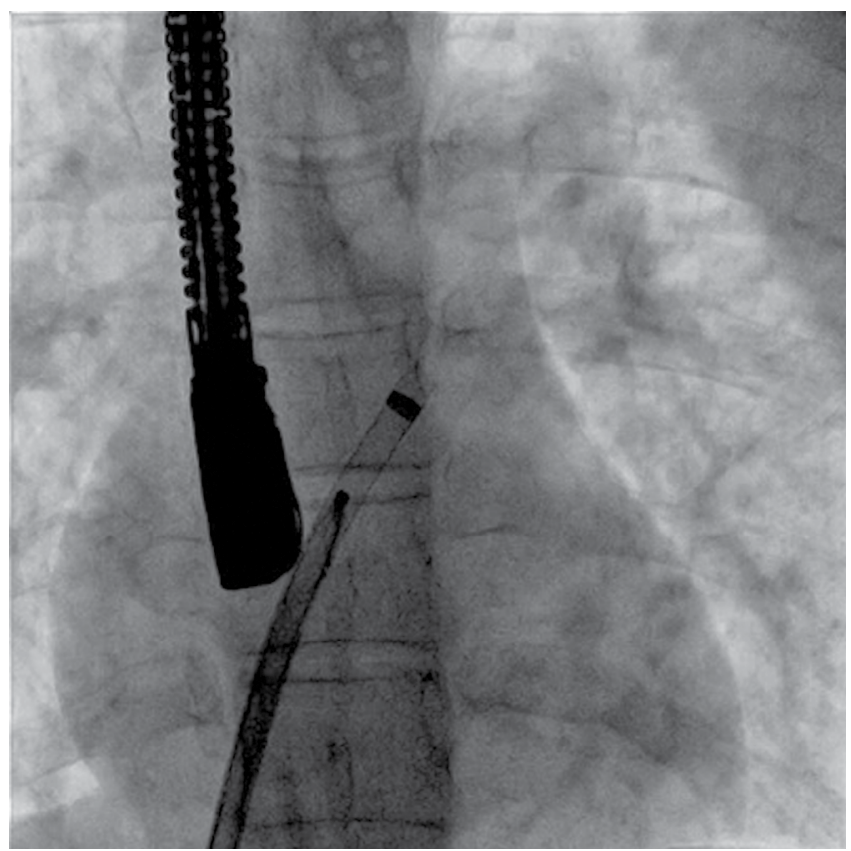

Video 17. Amplatzer septal occluder (ASO) is being passed through the delivery sheath. View supplementary video at http://dx.doi.org/10.12945/j.jshd.2016.007.14.vid.17.

Right frame: A floppy tip Amplatz Superstiff ${ }^{\mathrm{TM}}$ guide wire (Boston Scientific, Marlborough, Massachusetts, USA) being placed in the LSPV (Video 10). 


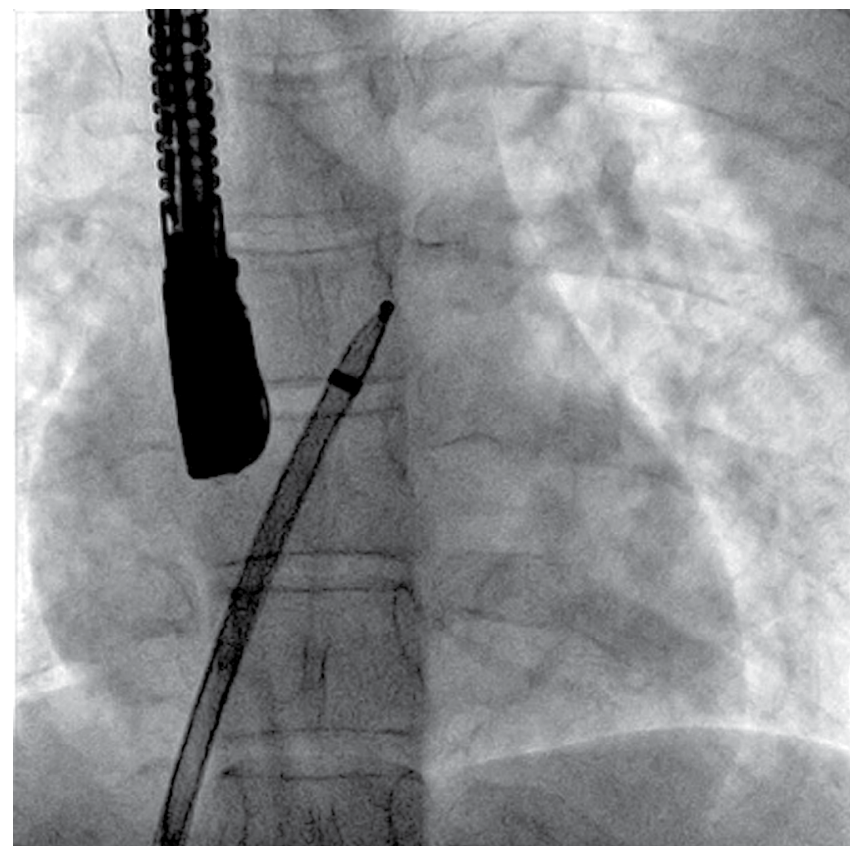

Video 18. Left atrial disk of the ASO being extruded in the left atrium. View supplementary video at http://dx.doi. org/10.12945/j.jshd.2016.007.14.vid.18.

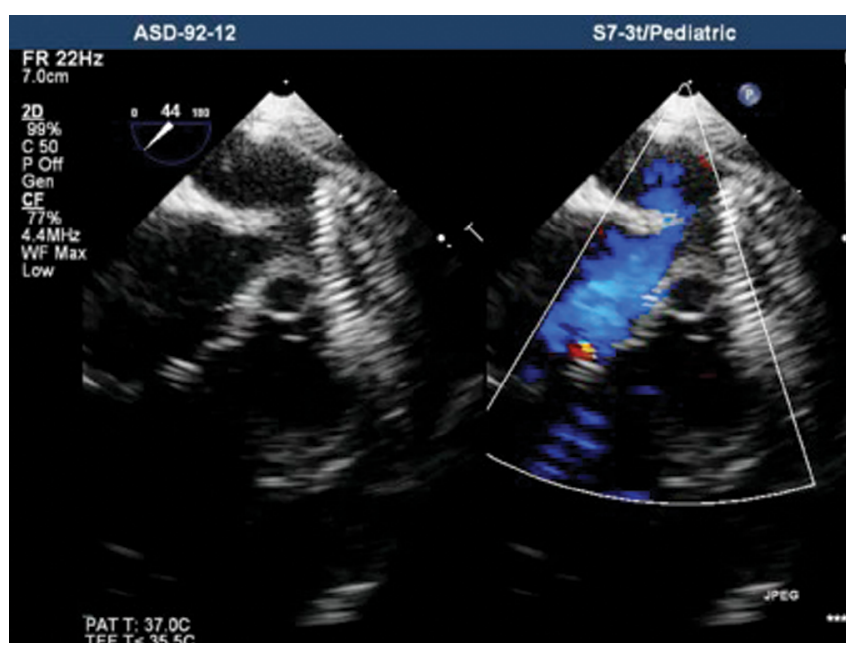

Video 19. Corresponding TEE loop showing left atrial disk in the left atrium. View supplementary video at http://dx.doi. org/10.12945/j.jshd.2016.007.14.vid.19.

\section{Slide \# 36:}

Left frame: An Amplatzer TorqVue ${ }^{\mathrm{TM}} 45^{\circ}$ delivery sheath (St. Jude, Plymouth, MN, USA) is passed over the Superstiff wire into the mouth of the LSPV (Video 11).

Right frame: Corresponding TEE loop showing the delivery sheath positioned in the LSPV (Video 12).

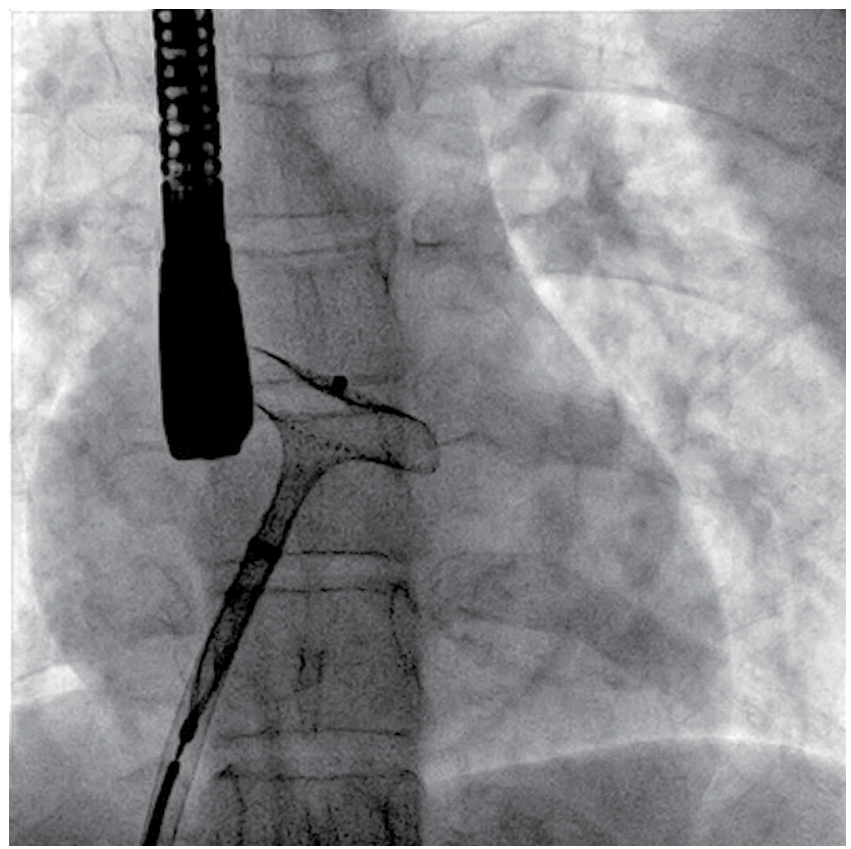

Video 20. The left atrial disk of the ASO being pulled back against the interatrial septum. View supplementary video at http://dx.doi.org/10.12945/j.jshd.2016.007.14.vid.20.

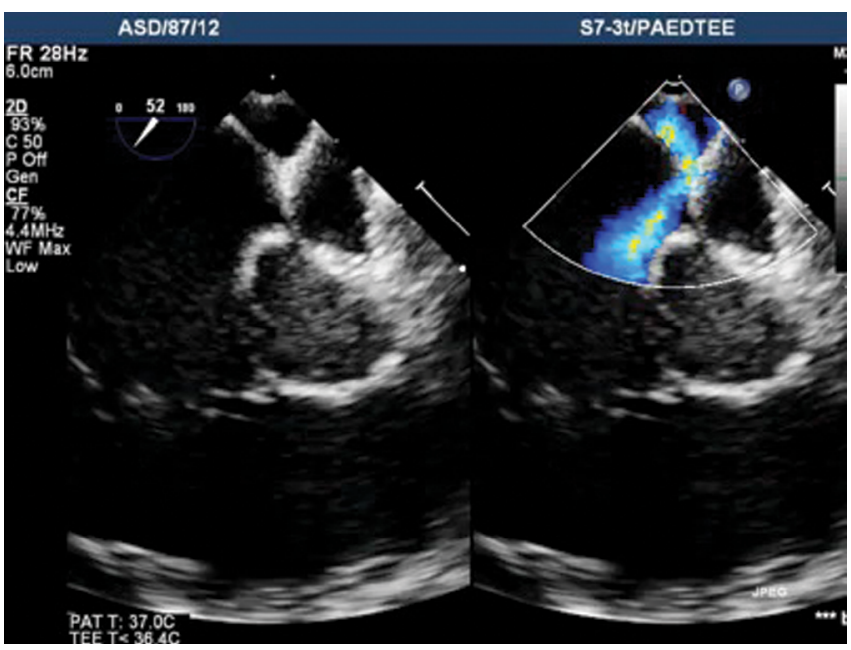

Video 21. Corresponding TEE loop depicting the same. View supplementary video at http://dx.doi.org/10.12945/j.jshd.2016.007.14. vid.21.

\section{Slide \# 37:}

Top left frame: Delivery sheath is advanced over the dilator into the mouth of LSPV (Video 13).

Top right frame: The delivery sheath positioned in the left atrium just outside the LSPV (Video 14). 


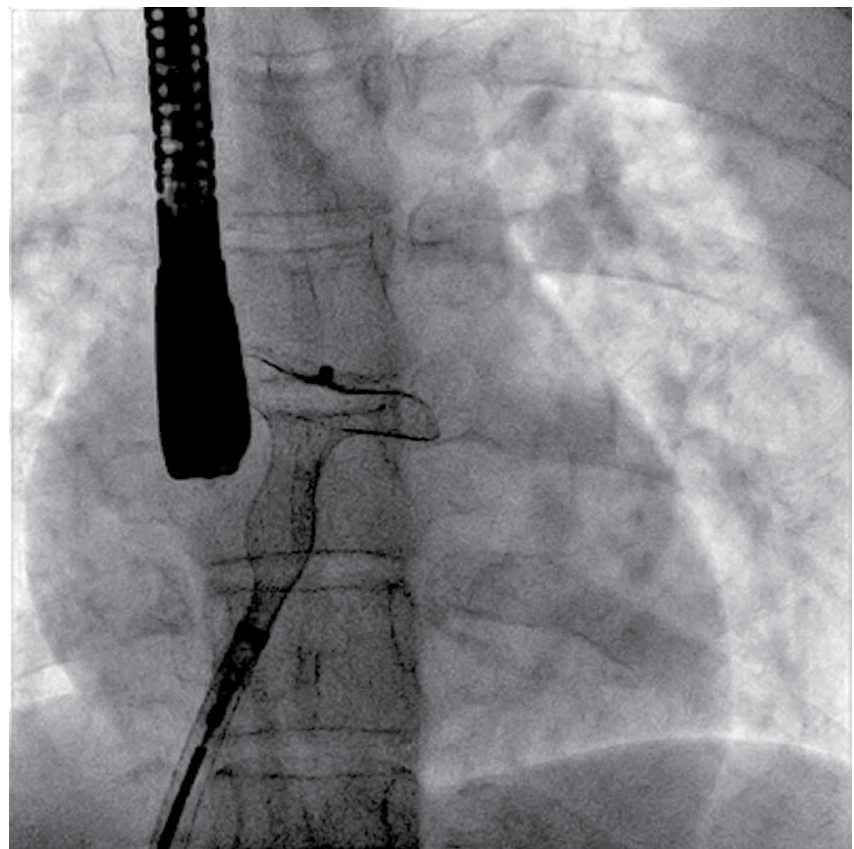

Video 22. Delivery sheath "peeled" back over the loading cable to allow release of the waist and the right atrial disk and deployment of device. View supplementary video at http://dx.doi. org/10.12945/j.jshd.2016.007.14.vid.22.

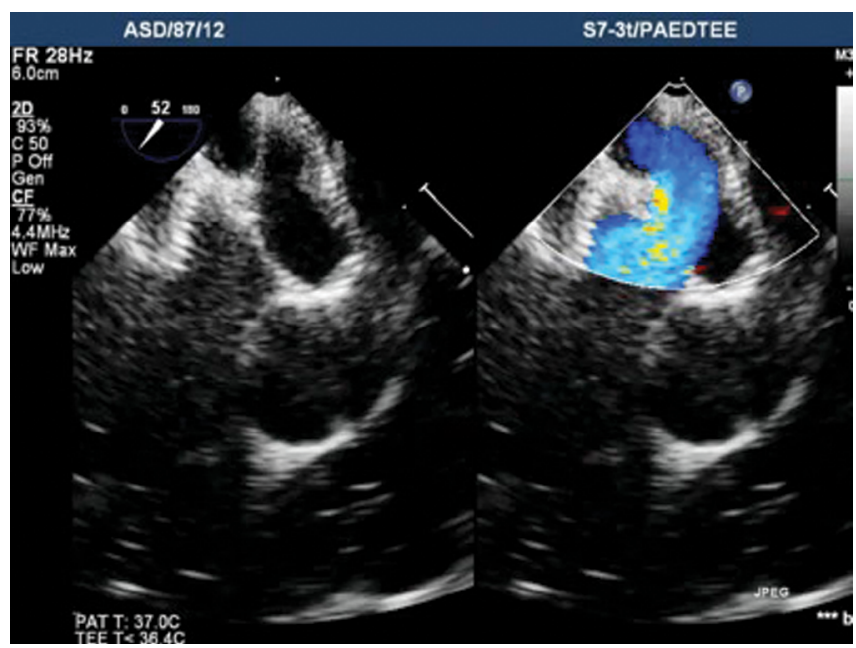

Video 23. Corresponding TEE loop depicting deployment of the ASO across the defect. View supplementary video at http:// dx.doi.org/10.12945/j.jshd.2016.007.14.vid.23.

Bottom frame: Corresponding TEE loop showing the sheath in the left atrium near the opening of the LSPV (Video 15).

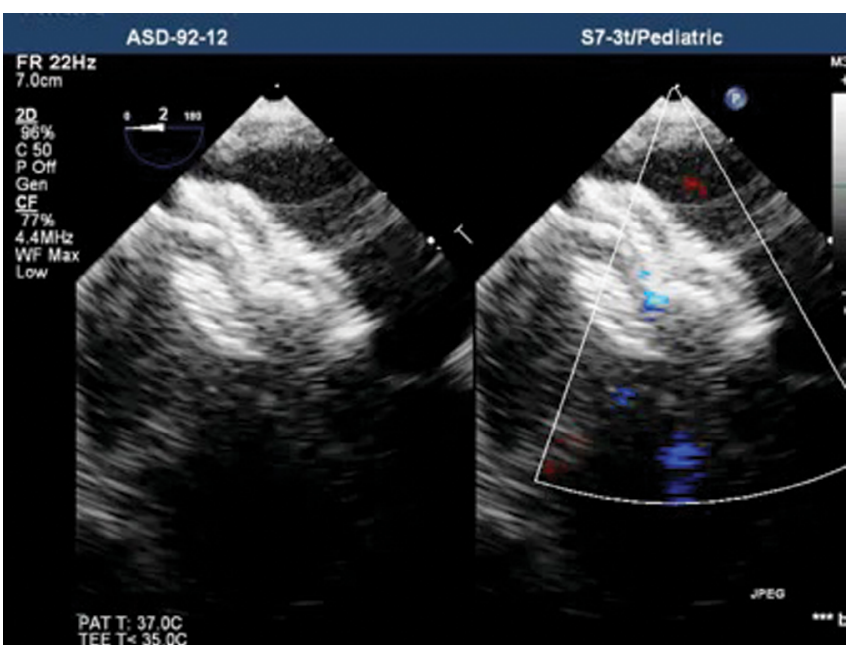

Video 24. TEE loops at 0 , confirming adequate capture of all margins before releasing the device from the loading cable. View supplementary video at http://dx.doi.org/10.12945/j. jshd.2016.007.14.vid.24.

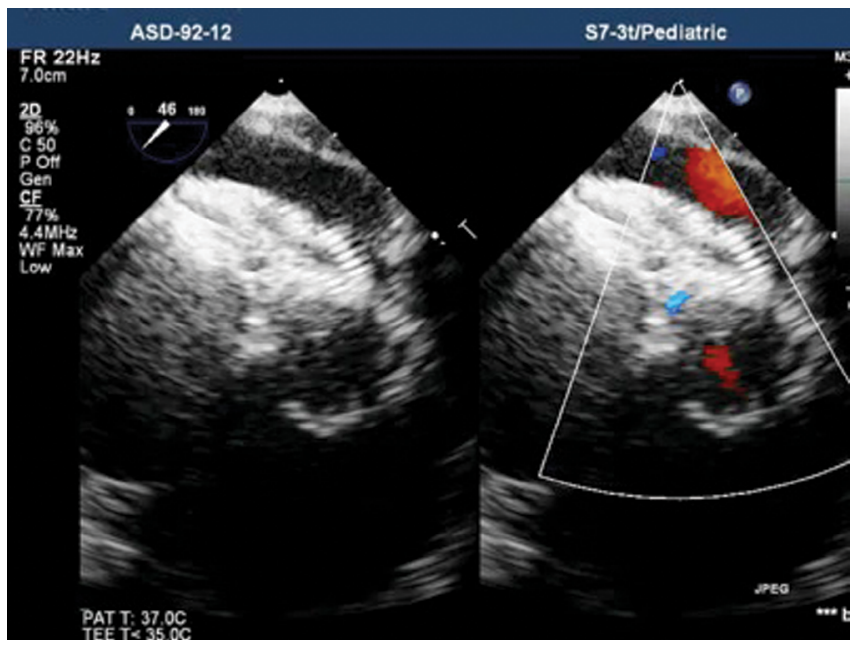

Video 25. TEE loops at 45, confirming adequate capture of all margins before releasing the device from the loading cable. View supplementary video at http://dx.doi.org/10.12945/j. jshd.2016.007.14.vid.25.

\section{Slide \# 38:}

Dilator is removed from the sheath to allow back bleed and prevent air embolism. If the patient is under GA with positive-pressure ventilation, one can back bleed as shown in this movie; but if the patient is breathing spontaneously, it is better to back bleed by holding the sheath below the level of the heart in a saline bowl. This helps in preventing inadvertent sucking of air into the sheath resulting in air embolism (Video 16). 


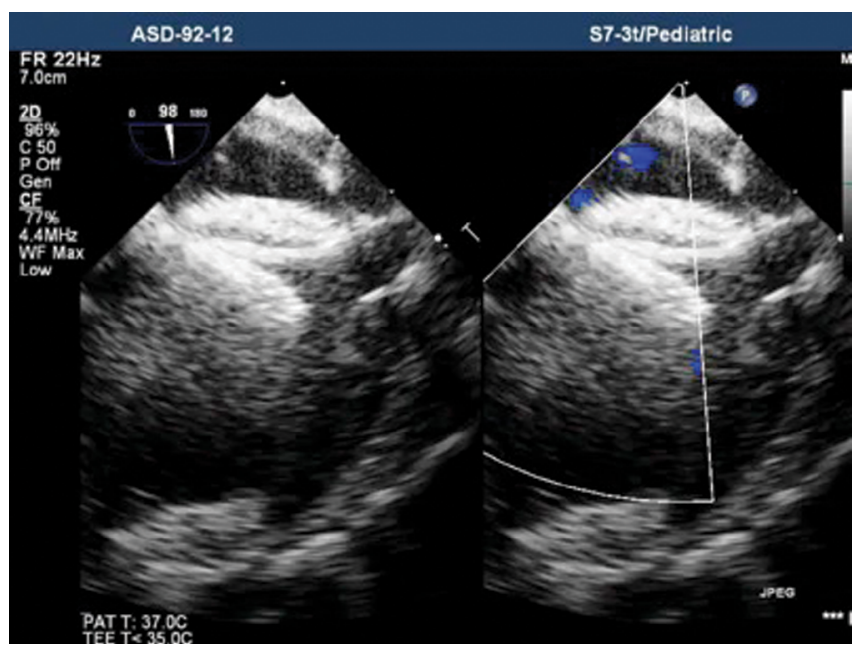

Video 26. TEE loops at 90 degrees, confirming adequate capture of all margins before releasing the device from the loading cable. View supplementary video at http://dx.doi.org/10.12945/j. jshd.2016.007.14.vid.26.

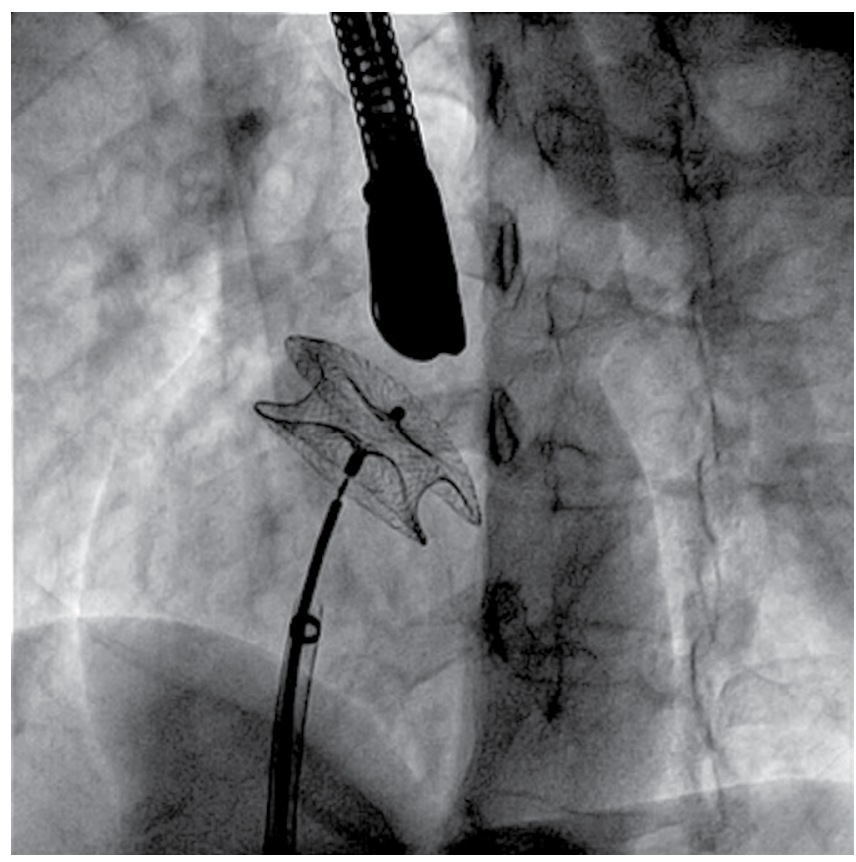

Video 27. Release of the ASO from loading cable in left anterior oblique (LAO) view. Note the well-separated disks of the ASO in LAO view confirming a well-positioned device. View supplementary video at http://dx.doi.org/10.12945/j.jshd.2016.007.14.vid.27.

\section{Slide \# 39:}

Top left frame: Amplatzer septal occluder (ASO) is passed through the delivery sheath (Video 17).

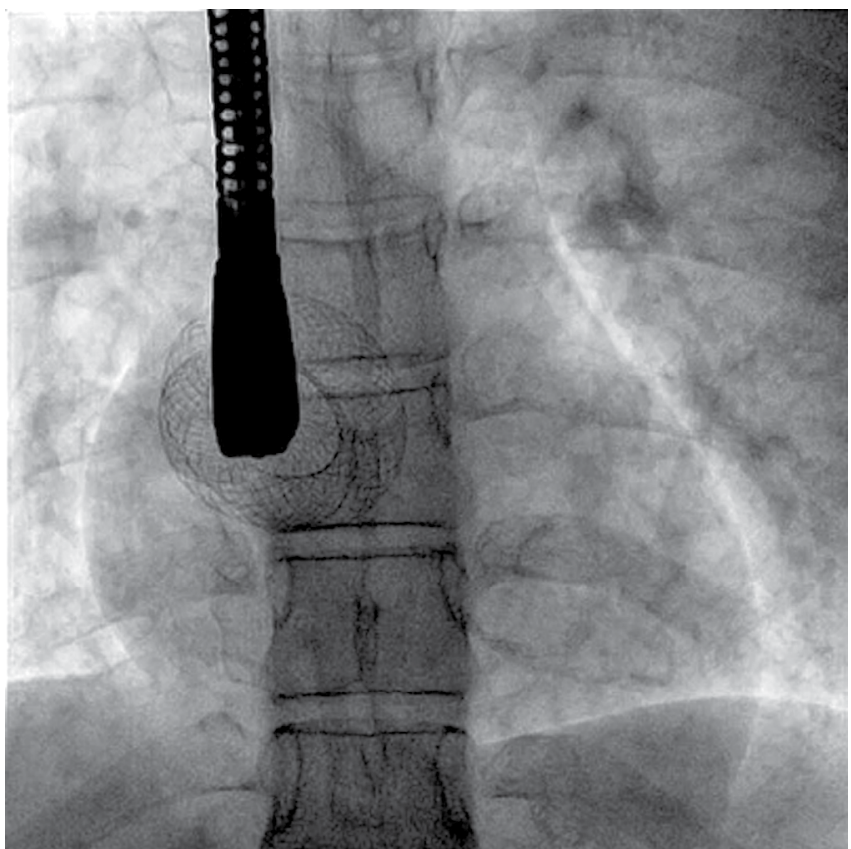

Video 28. Final position of the device in anteroposterior projection; fluroscopic "fingerprinting" of the device. View supplementary video at http://dx.doi.org/10.12945/j.jshd.2016.007.14.vid.28.

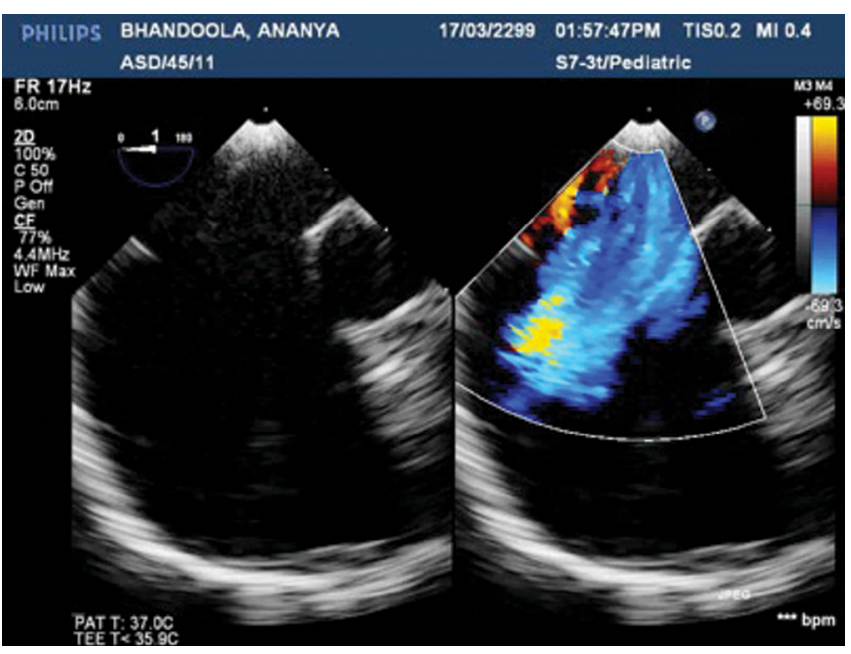

Video 29. TEE loops depicting a large ASD in a small child. The left atrium is relatively smaller compared to the right atrium. View supplementary video at http://dx.doi.org/10.12945/j. jshd.2016.007.14.vid.29.

Top right frame: Left atrial disk of the ASO is extruded in the left atrium (Video 18).

Bottom frame: Corresponding TEE loop showing left atrial disk in the left atrium (Video 19). 


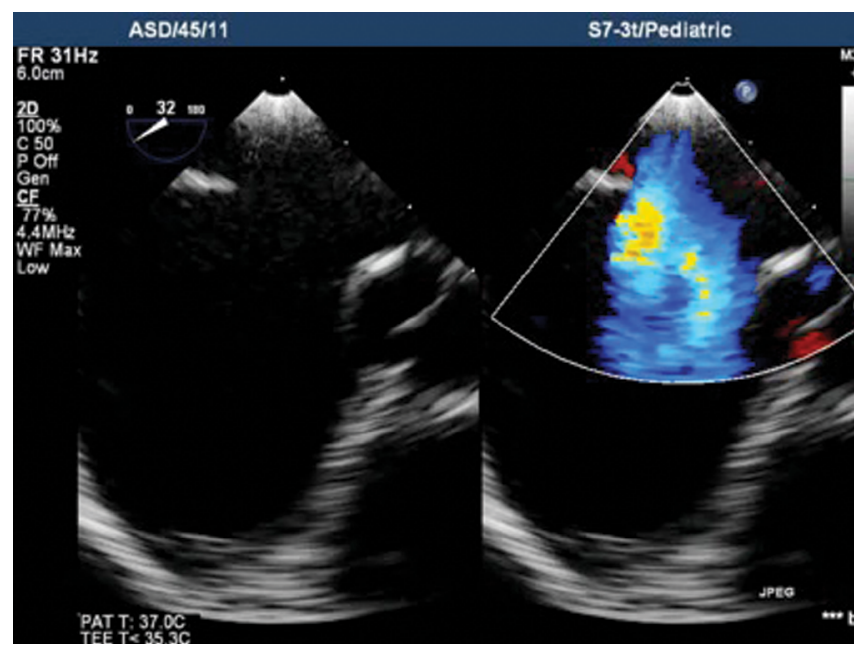

Video 30. TEE loops depicting a large ASD in a small child. The left atrium is relatively smaller compared to the right atrium. View supplementary video at http://dx.doi.org/10.12945/j. jshd.2016.007.14.vid.30.

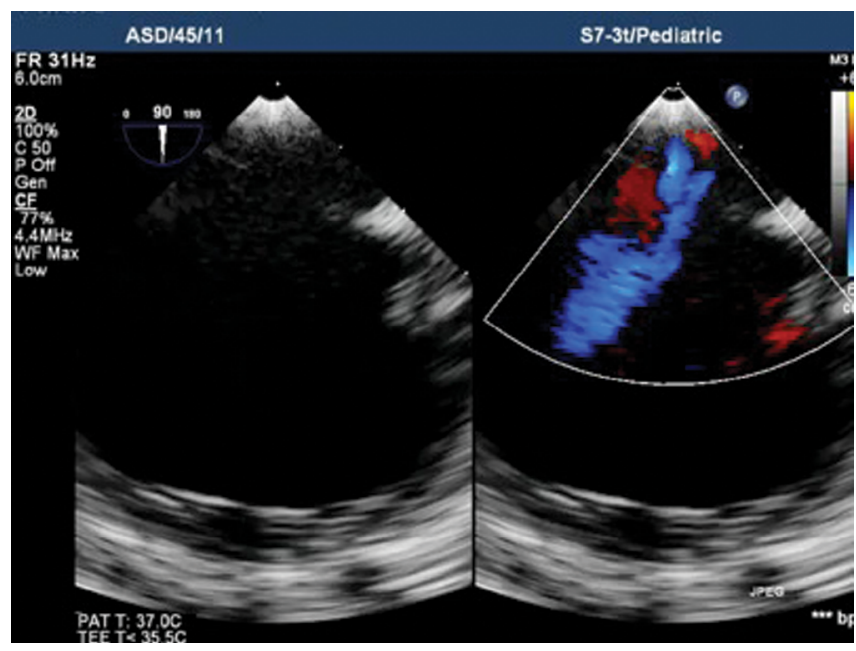

Video 31. TEE loops depicting a large ASD in a small child. The left atrium is relatively smaller compared to the right atrium. View supplementary video at http://dx.doi.org/10.12945/j. jshd.2016.007.14.vid.31.

\section{Slide \# 40:}

Left frame: The left atrial disk of the ASO is pulled back against the interatrial septum (Video 20).

Right frame: Corresponding TEE loop depicting the same (Video 21).

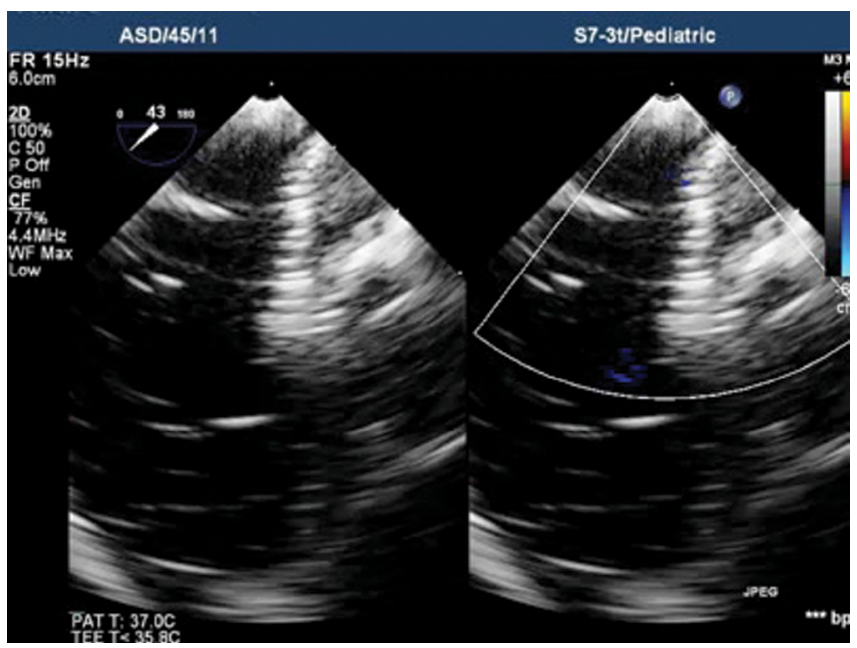

Video 32. TEE depicting the left atrial disk lying perpendicular to the atrial septum due to inability to accommodate the disk in the left atrium. View supplementary video at http://dx.doi. org/10.12945/j.jshd.2016.007.14.vid.32.

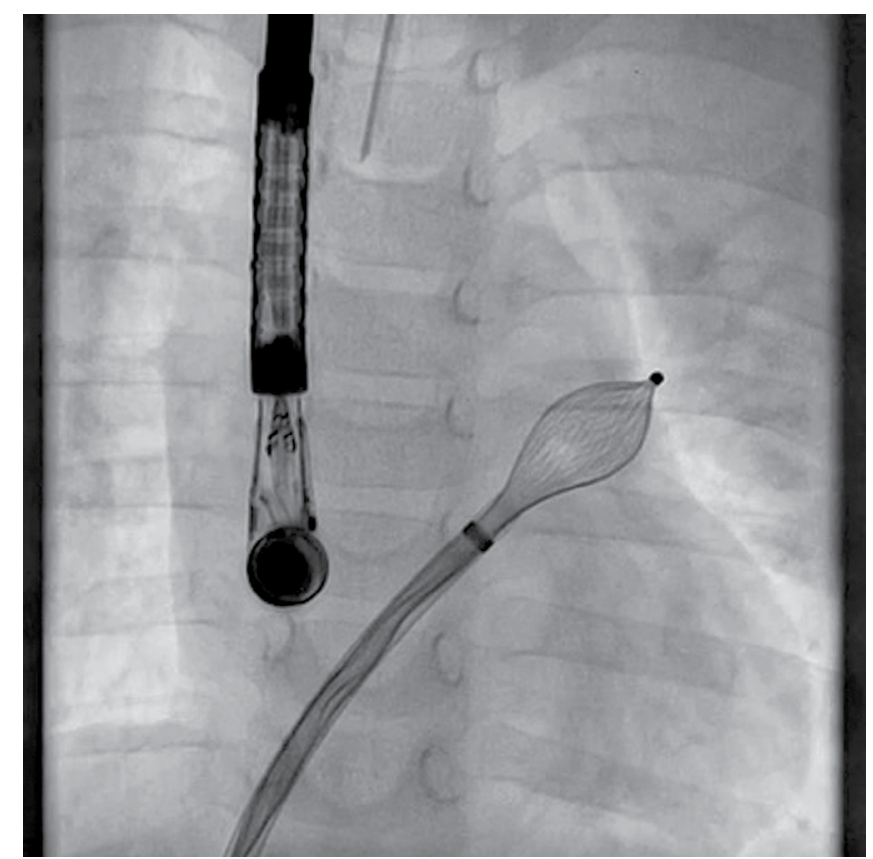

Video 33. ASO being deployed via LSPV technique that is engaging the LA disk into LSPV. The LA disk disengagement was spontaneous. View supplementary video at http://dx.doi. org/10.12945/j.jshd.2016.007.14.vid.33.

Slide \# 41:

Left frame: Delivery sheath "peeled" back over the loading cable to allow release of the waist 


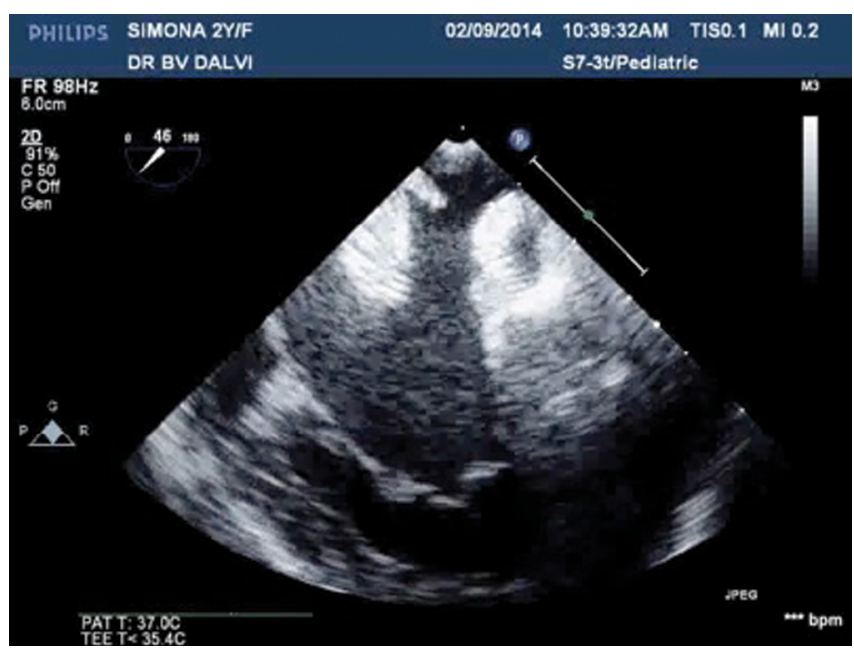

Video 34. Corresponding TEE loop depicting the LSPV technique. View supplementary video at http://dx.doi.org/10.12945/j. jshd.2016.007.14.vid.34.

and the right atrial disk and deployment of device (Video 22).

Right frame: Corresponding TEE loop depicting deployment of the ASO across the defect (Video 23).

\section{Slide \# 42:}

TEE loops at 0 (top left), 45 (top right), and 90 degrees (bottom), confirming adequate capture of all margins before releasing the device from the loading cable (Videos 24, 25, and 26, respectively).

Slide \# 43:

Left frame: Release of the ASO from loading cable in left anterior oblique (LAO) view. Note the well-separated disks of the ASO in LAO view confirming a well-positioned device (Video 27).

Right frame: Final position of the device in anteroposterior projection; fluroscopic "fingerprinting" of the device (Video 28).

\section{Slide \# 46:}

Top frames and bottom left frame: TEE loops depicting a large ASD in a small child. The left atrium is relatively smaller compared to the right atrium (Videos 29, 30, and 31).

Bottom right frame: TEE depicting the left atrial disk lying perpendicular to the atrial septum due to

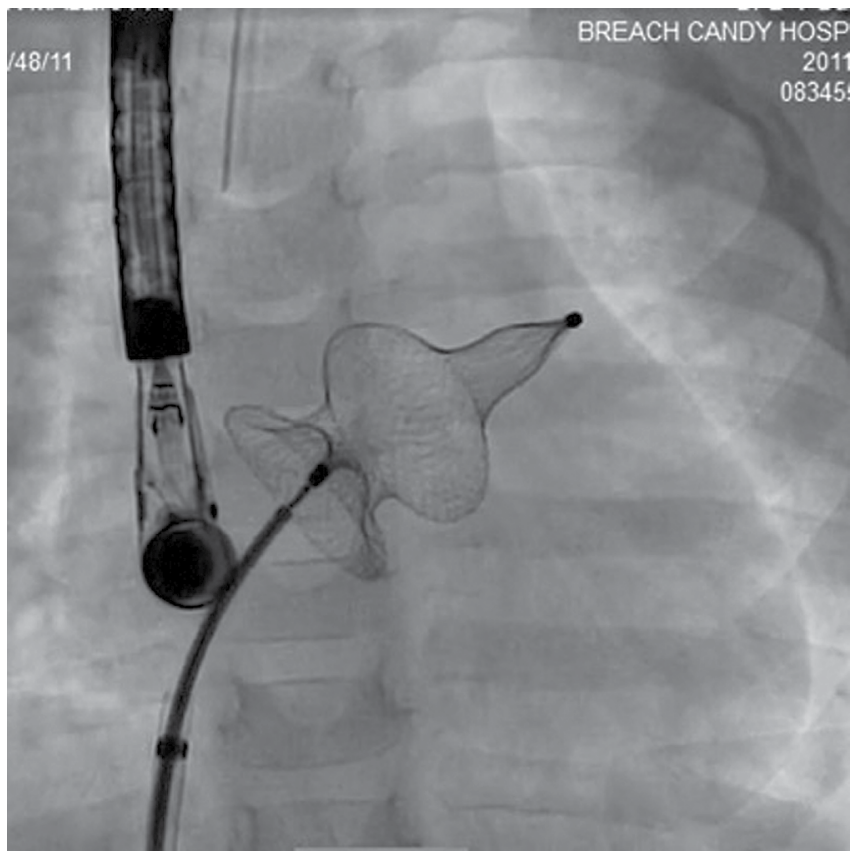

Video 35. A contrarian technique of pushing on the cable rather than pulling, to disengage the LA disk. View supplementary video at http://dx.doi.org/10.12945/j.jshd.2016.007.14. vid.35.

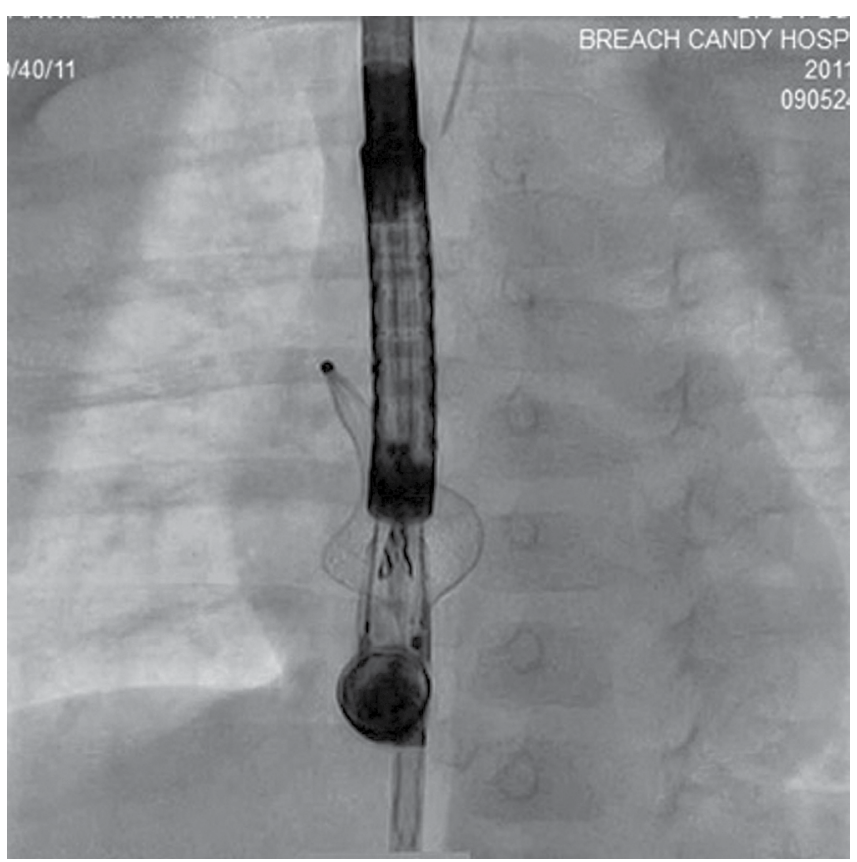

Video 36. ASO is deployed with the left atrial disk being engaged into the right superior pulmonary vein. Loading cable is pushed to disengage the let atrial disk from the RSPV. View supplementary video at http://dx.doi.org/10.12945/j.jshd.2016.007.14.vid.36. 


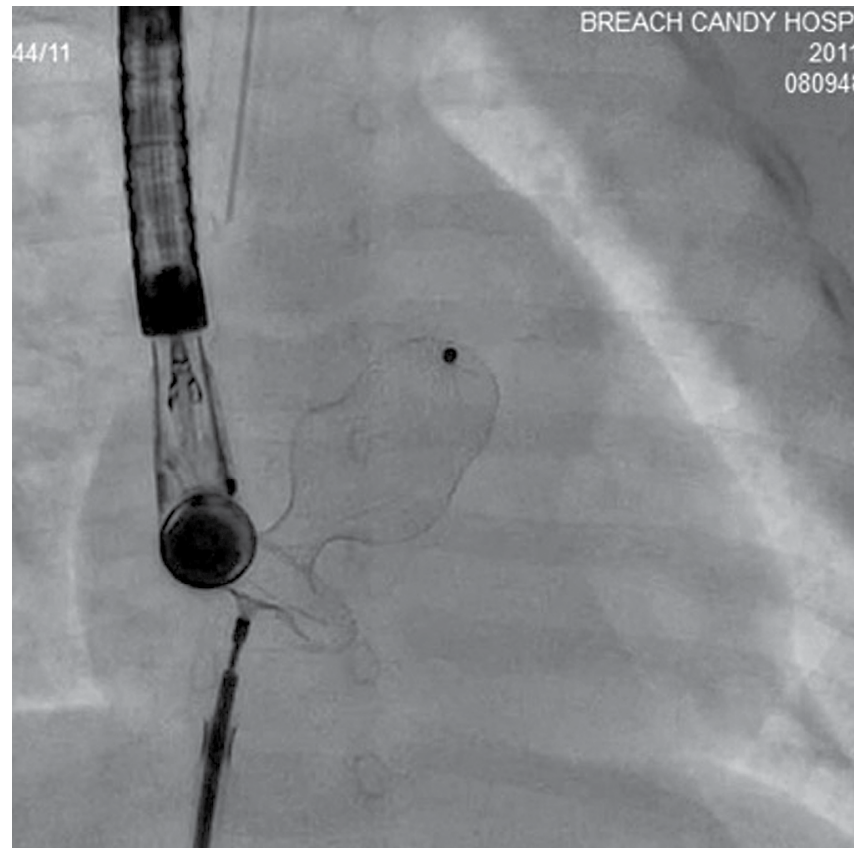

Video 37. ASO is deployed with the left atrial disk engaged in the left atrial appendage. Similar to the previous case, the LA disk has been disengaged from the LA appendage by pushing the loading cable. View supplementary video at http://dx.doi. org/10.12945/j.jshd.2016.007.14.vid.37.

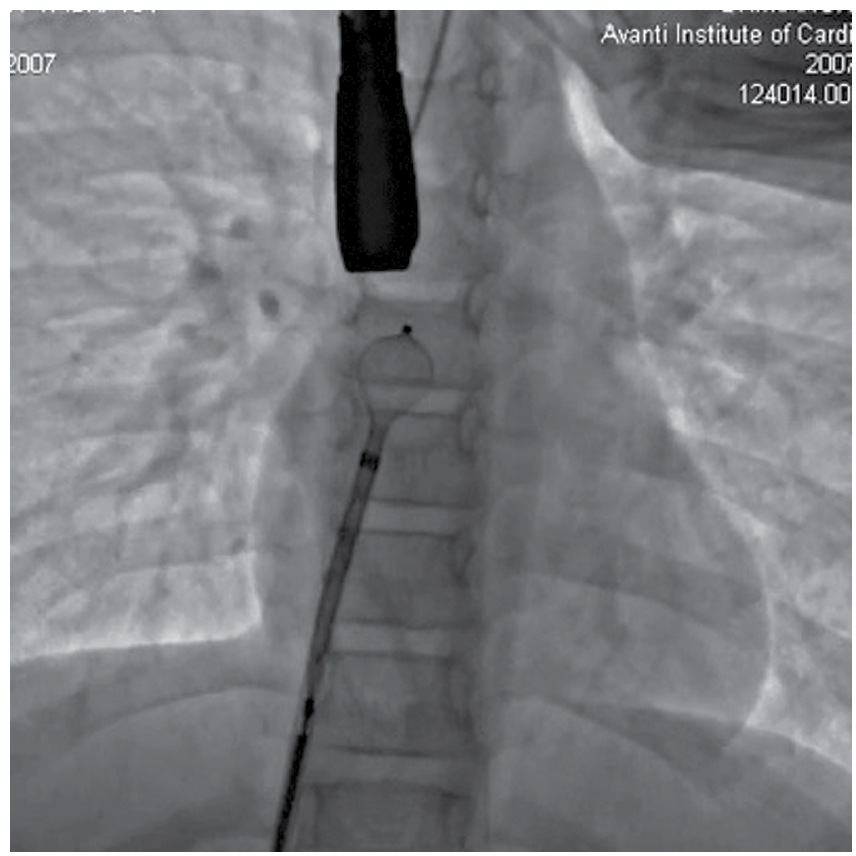

Video 38. The delivery sheath has been positioned outside the right superior pulmonary vein instead of LSPV to prevent malalignment of the device disks with the interatrial septum. View supplementary video at http://dx.doi.org/10.12945/j. jshd.2016.007.14.vid.38.

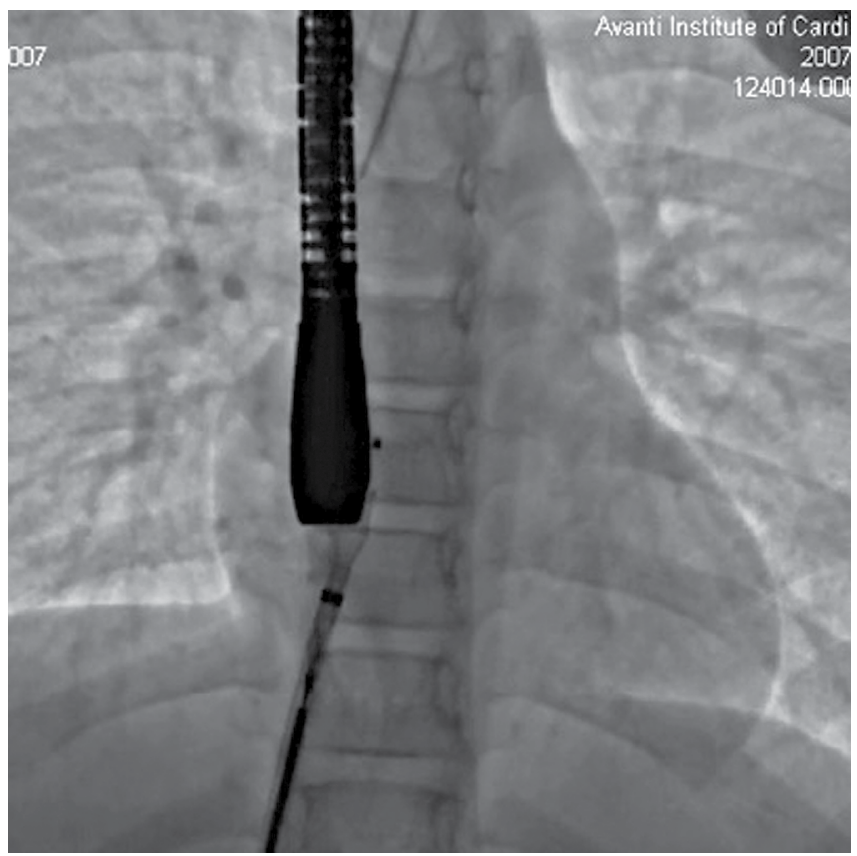

Video 39. The ASO device being deployed by this technique. View supplementary video at http://dx.doi.org/10.12945/j. jshd.2016.007.14.vid.39.

inability to accommodate the disk in the left atrium (Video 32).

\section{Slide \# 48:}

Left frame: ASO being deployed via LSPV technique that is engaging the LA disk into LSPV. The LA disk disengagement was spontaneous (Video 33). Similarly the left atrial disc can be engaged in the right superior pulmonary vein or the left atrial appendage.

Right frame: Corresponding TEE loop depicting the LSPV technique (Video 34).

\section{Slide \# 49:}

Left frame: If the LA disk does not disengage spontaneously, there is a tendency to pull on the loading cable to disengage the disk. In doing so, the RA disk tends to lose its alignment with the IAS and the LA disk tends to fall through the defect in the RA. We have used a contrarian technique of pushing on the cable rather than pulling, to disengage the LA disk. This creates a secondary torque on the LA disc, resulting in its disengagement from the LSPV while maintaining the alignment of the right atrial disk with the interatrial septum (Video 35). 


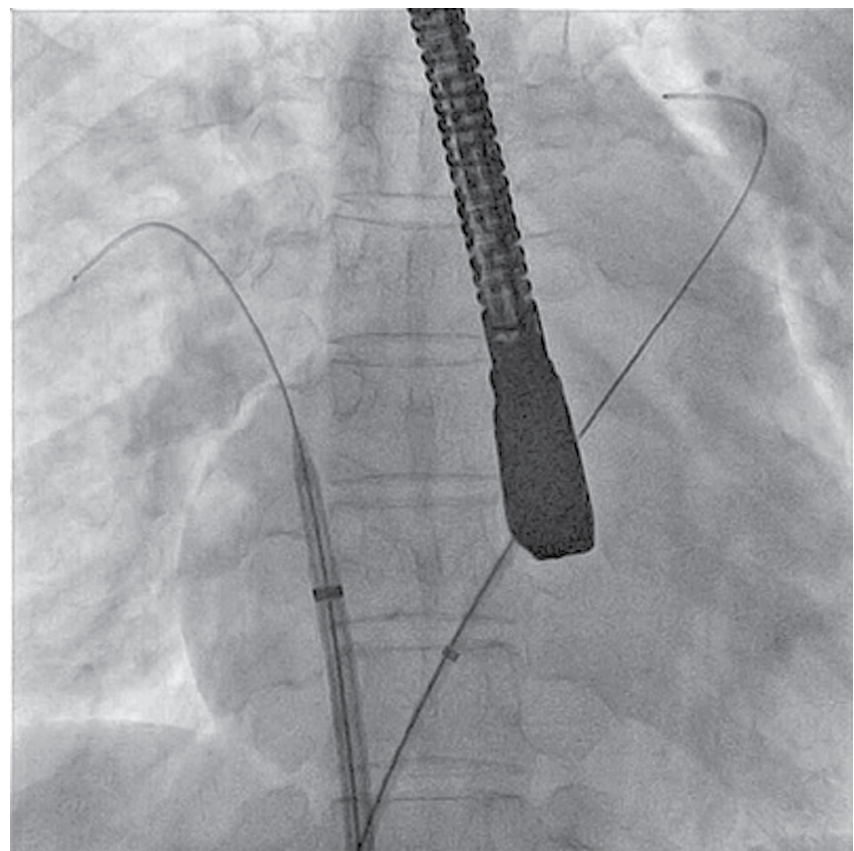

Video 40. An Occlutech balloon is positioned in the right atrium and pushed against the interatrial septum over a Superstiff wire positioned in the LSPV. View supplementary video at http:// dx.doi.org/10.12945/j.jshd.2016.007.14.vid.40.

Middle frame: ASO is deployed with the left atrial disk engaged into the right superior pulmonary vein. Loading cable is pushed to disengage the let atrial disk from the RSPV (Video 36).

Right frame: ASO is deployed with the left atrial disk engaged in the left atrial appendage. Similar to the previous case, the LA disk has been disengaged from the LA appendage by pushing the loading cable (Video 37).

\section{Slide \# 51:}

Left frame: The delivery sheath has been positioned outside the right superior pulmonary vein instead of LSPV to prevent malalignment of the device disks with the interatrial septum (Video 38).

Right frame: The ASO device is deployed by this technique (Video 39).

\section{Slide \# 52:}

Left frame: Hausdorf sheath (Cook, Bloomington, Indiana, USA) is a specially designed long sheath with two posterior curves at its end, allowing for a

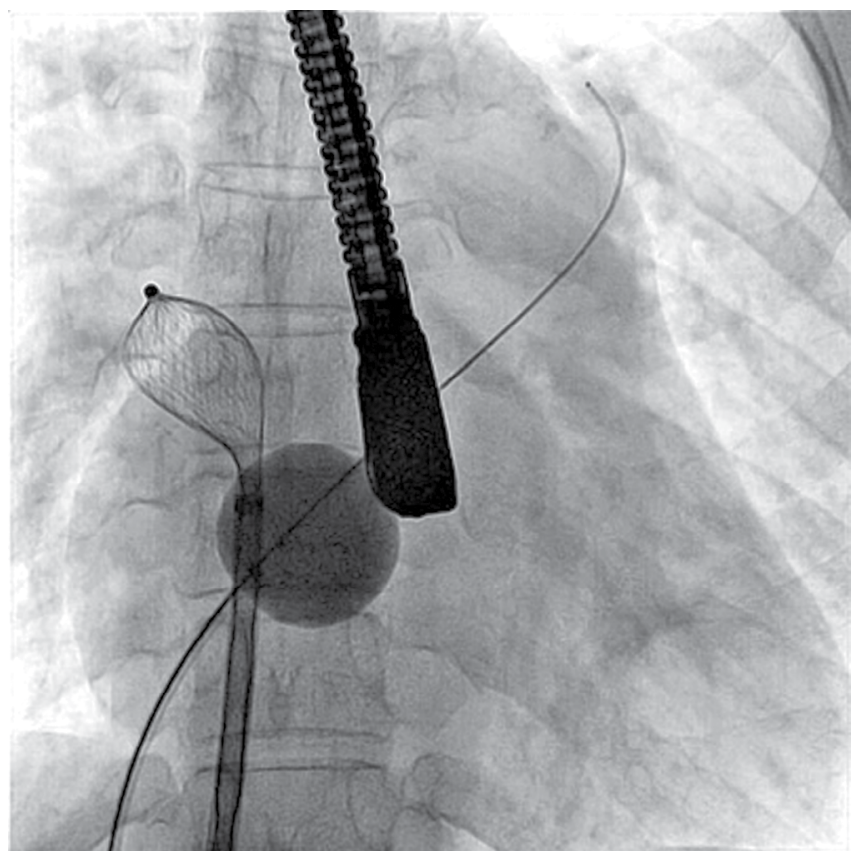

Video 41. The balloon is inflated followed by sequential release of the left atrial disk, waist and the right atrial disk. Superstiff wire positioned in the LSPV. View supplementary video at http://dx. doi.org/10.12945/j.jshd.2016.007.14.vid.41

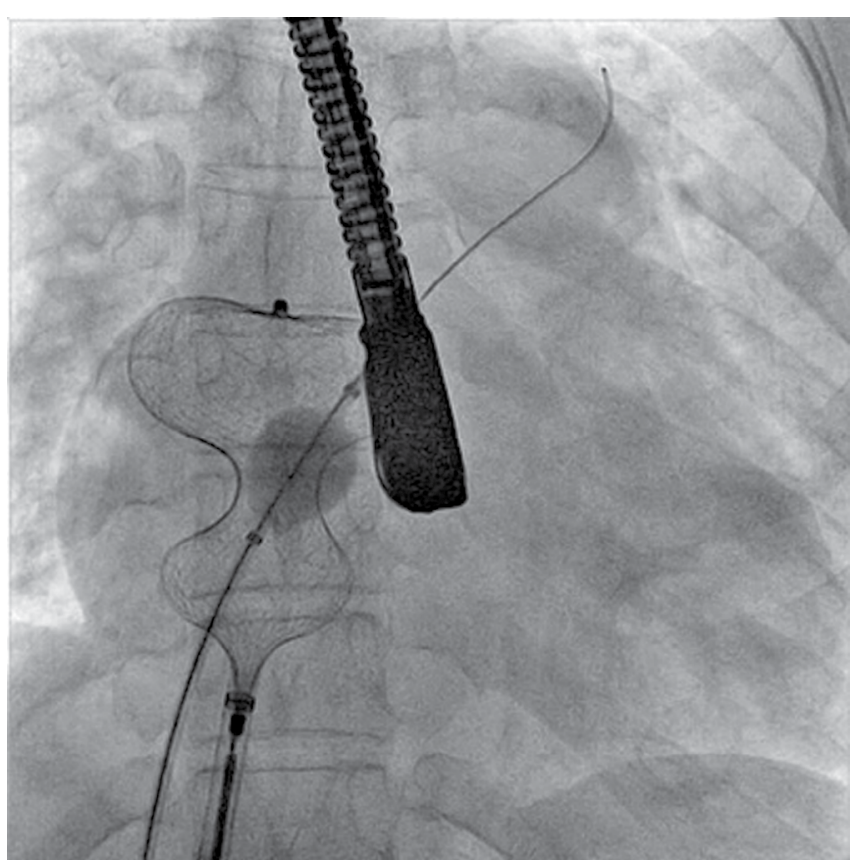

Video 42. The balloon is gradually deflated to allow deployment of the device across the ASD. Superstiff wire positioned in the LSPV. View supplementary video at http://dx.doi. org/10.12945/j.jshd.2016.007.14.vid.42. 


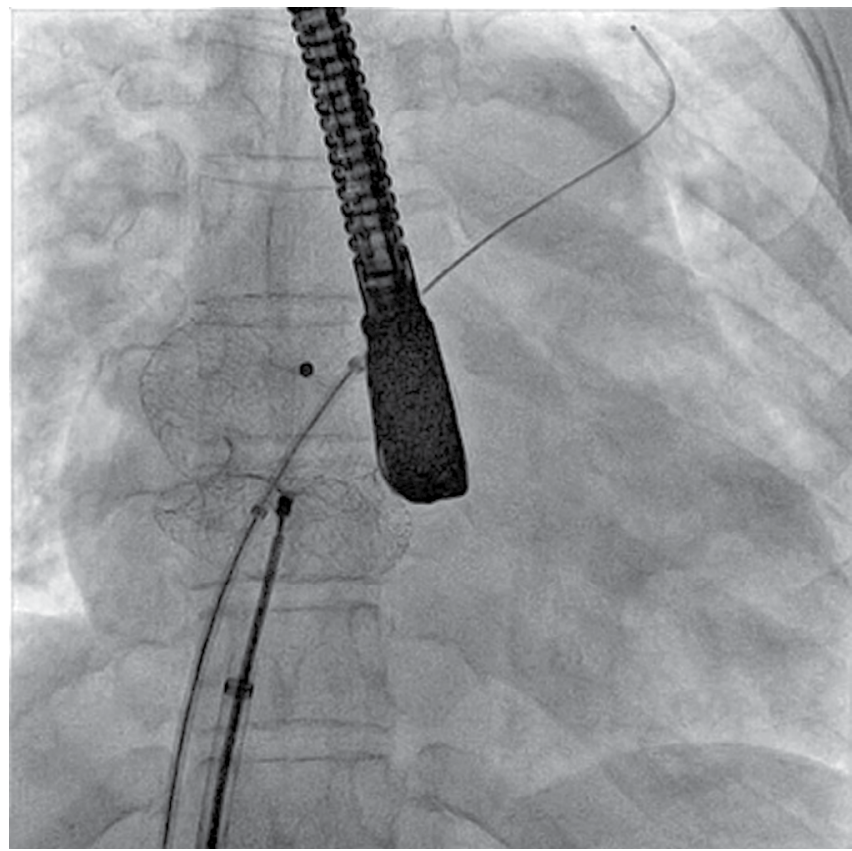

Video 43. The balloon catheter is pulled back into the inferior vena cava before releasing the device. View supplementary video at http://dx.doi.org/10.12945/j.jshd.2016.007.14.vid.43.

better alignment of the left atrial disk parallel to the septum [16].

Right frame: Sidecutting sheath is a modified Mullins sheath with the creation of a bevel at the inner curvature, also allowing a more parallel alignment of the left atrial disk to the interatrial septum [17].

\section{Slide \# 53:}

Wahab technique (Dilator-assisted technique): Following deployment of the left atrial disk, a long dilator is advanced into the left atrium, holding the anterosuperior part of the left atrial disk to prevent it from prolapsing [18].

\section{Slide \# 54:}

*Balloon assisted technique [19]:

Left frame: An Occlutech balloon (Boston Scientific, Watertown, Massachusetts, USA) is positioned in the right atrium and pushed against the interatrial septum over a Superstiff wire positioned in the LSPV. The ASO delivery sheath is positioned in the right superior pulmonary vein (Video 40).

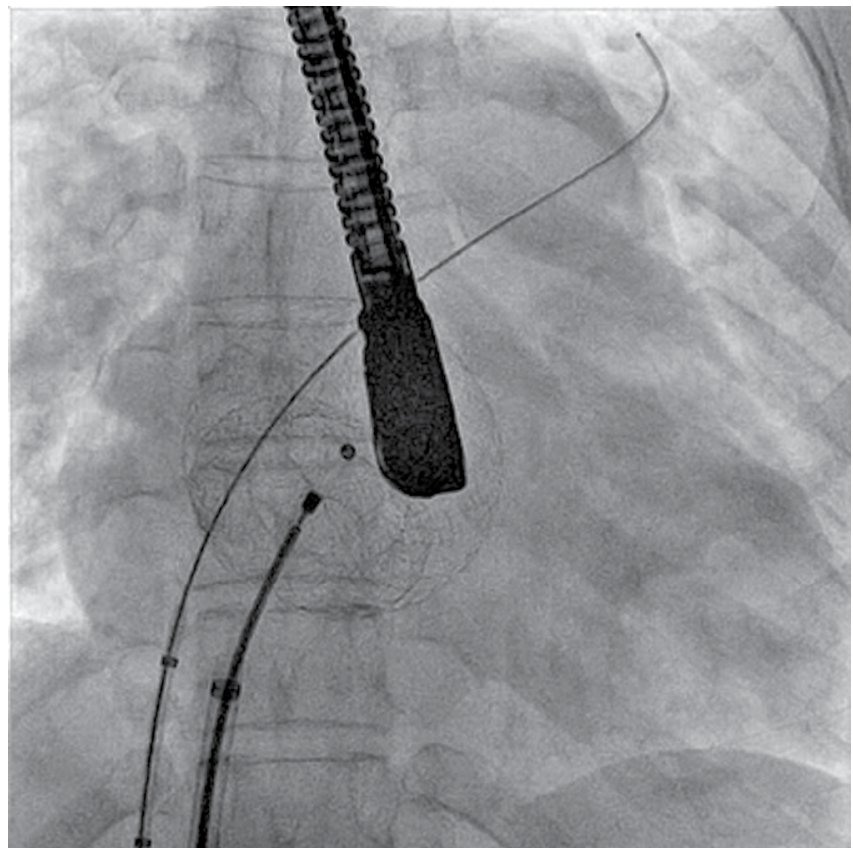

Video 44. The Superstiff wire now pulled back into the inferior vena cava before releasing the device. View supplementary video at http://dx.doi.org/10.12945/j.jshd.2016.007.14. vid.44.

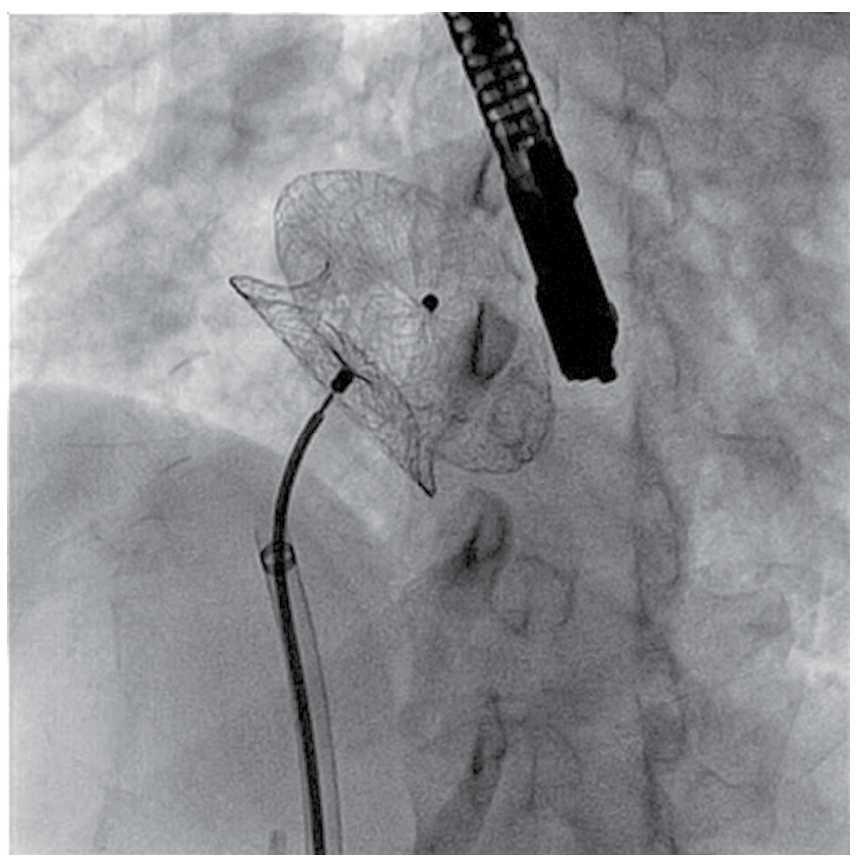

Video 45. Device position confirmed in left anterior oblique view and released. View supplementary video at http://dx.doi. org/10.12945/j.jshd.2016.007.14.vid.45. 
Middle frame: The balloon is inflated followed by sequential release of the left atrial disk, waist and the right atrial disk (Video 41).

Right frame: The balloon is gradually deflated to allow deployment of the device across the ASD (Video 42). The advantages of BAT are that it is a simple and safe procedure, is effective across all ages, has a short learning curve and is predictable. Its limitations include requiring an additional venous access, additional hardware (cost), need for additional personnel, large venous access and problems pertaining to hemostasis.

\section{Slide \# 55:}

Left frame: The balloon catheter is pulled back into the inferior vena cava before releasing the device (Video 43).

Middle frame: The Superstiff wire now pulled back into the inferior vena cava before releasing the device (Video 44).

Right frame: Device position confirmed in left anterior oblique view and released (Video 45).

\section{Slide \# 57:}

BAT modification by Kammache et al. [20]:

Major differences in this modified technique include:

1. The sizing balloon (Meditech, Boston Scientific, Watertown, Massachusetts, USA) is positioned in the septal defect or even within the left atrium in order to use it as a rim to anchor the device.

2. The left atrial disk is delivered in the left atrium rather than just outside the superior pulmonary vein.

3. The authors recommend gentle tug on the delivery cable (Minnesota wiggle) to ascertain secure device position since the balloon, and not the rim, is used as a support during device deployment.

Slide \# 58:

BAT modification by Wahab et al. [21]:

This technique utilizes a regular sizing balloon that is positioned across the atrial septal defect to prevent prolapse of the left atrial disk.

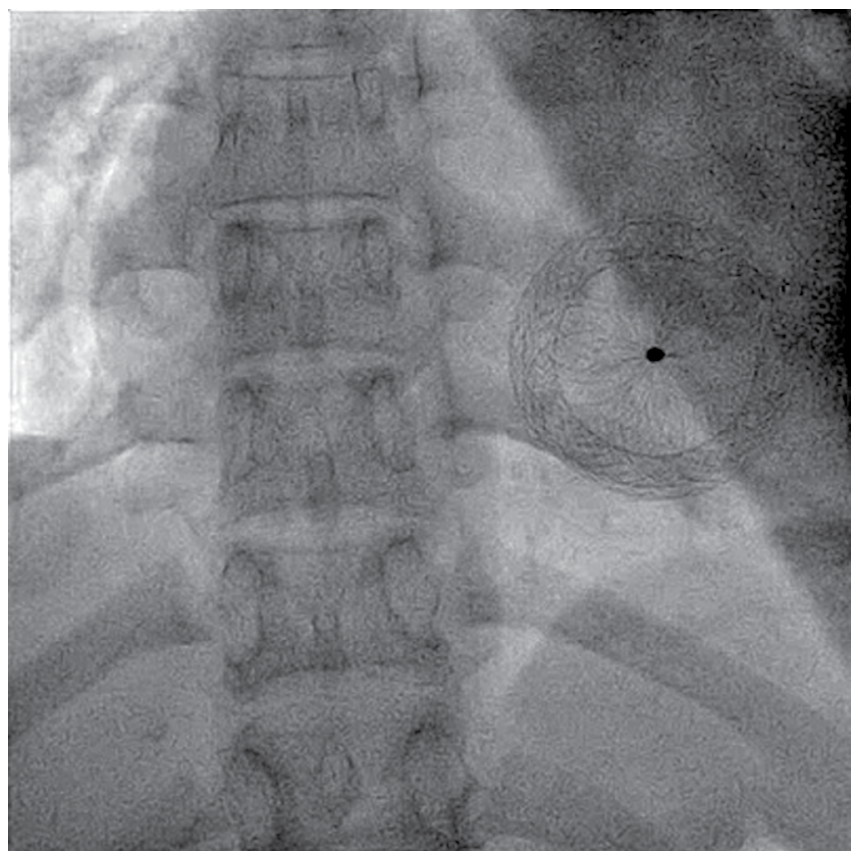

Video 46. ASO embolized to the right ventricle. View supplementary video at http://dx.doi.org/10.12945/j.jshd.2016.007.14. vid.46.

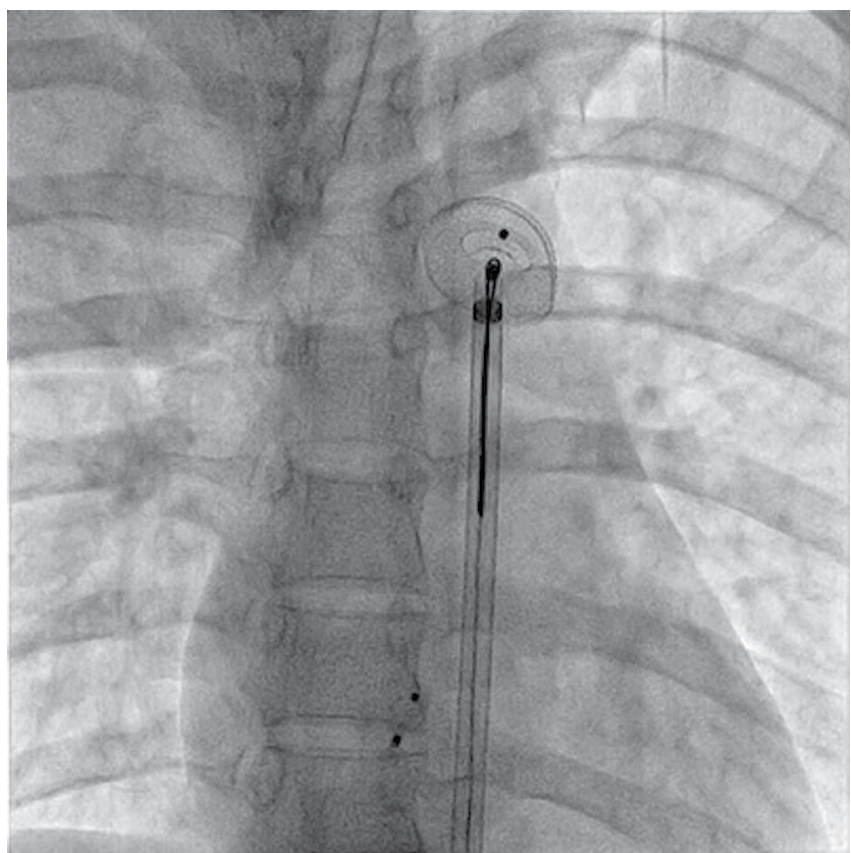

Video 47. ASO being retrieved from the descending thoracic aorta. View supplementary video at http://dx.doi.org/10.12945/j. jshd.2016.007.14.vid.47. 


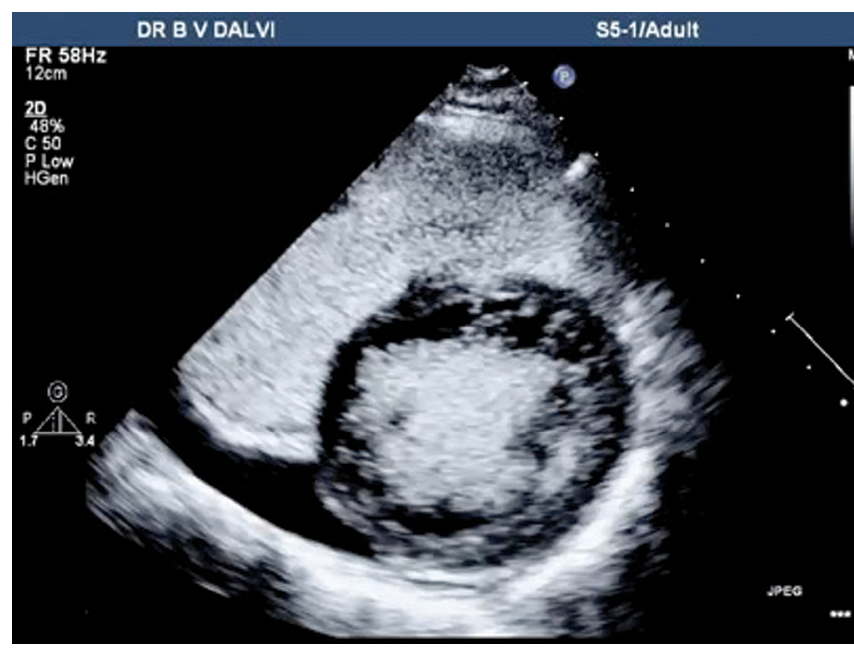

Video 48. Absence of leak of contrast agent into the pericardial space after appearing in all the four cardiac chambers. View supplementary video at http://dx.doi.org/10.12945/j. jshd.2016.007.14.vid.48.

\section{Slide \# 61:}

Air embolism:

- Evident by ST segment changes (left frame).

- Usually transient (right frame)

- Can be avoided by consciously avoiding injecting air through peripheral lines and checking for adequate back flow of blood from catheters and sheaths placed in the left atrium/pulmonary vein.

Slide \# 65:

Device embolization:

- Rare complication (0.55\%) [24]

- Usually occurs in those with large ASD and deficient rims. Can embolize to either side of the atrial septum (left frame: ASO embolized to the right ventricle; Video 46)

- Majority do not cause acute hemodynamic collapse

- Most can be snared and retrieved percutaneously (right frame: ASO being retrieved from the descending thoracic aorta; Video 47); principles of percutaneous device retrieval have been well described in the literature [25]

Slide \# 68:

Use of ultrasound contrast agent during echocardiography can help diagnose cardiac erosion. The above video depicts absence of leak of contrast agent into the pericardial space after appearing in all the four cardiac chambers (Video 48). Patient was managed medically with close supervision to observe for any evidence of hemodynamic compromise or increase in the amount of pericardial effusion. The effusion reduced gradually followed by complete disappearance on medical management.

\section{Acknowledgements}

The authors would like to thank Dr. Larry Latson for providing an image for this article.

\section{Conflict of Interest}

Bharat Dalvi is a consultant for St. Jude Medical.

\section{Comment on this Article or Ask a Question}

\section{References}

1. King TD, Mills NL. Non-operative closure of atrial septal defects. Surgery. 1974;75:383388.

2. Feltes $T F$, Bacha $E$, Beekman $R H$ 3rd, Cheatham JP, Feinstein JA, Gomes AS, et al.Indications for cardiac catheterization and intervention in pediatric cardiac disease: A scientific statement from the American Heart Association. Circulation. 2011;123:2607-2652. DOI: 10.1161/
CIR.0b013e31821b1f10

3. Warnes CA, Williams RG, Bashore TM, Child JS, Connolly HM, Dearani JA, et al. ACC/ AHA 2008 guidelines for the management of adults with congenital heart disease. J Am Coll Cardiol. 2008;52:e143-263. DOI: 10.1016/j.jacc.2008.10.001 and 10.1016/j. jacc.2008.10.002

4. Webb G, Gatzoulis MA. Atrial septal defects in the adults: Recent progress and overview. Circulation. 2006;114:16451653. DOI: $10.1161 /$ CIRCULATIONAHA.105.592055

5. Jung JW. Echocardiographic evaluation of atrial septal defect device closure. J Cardiovasc Ultrasound. 2007;15:1-7.

6. Vaidyanathan B, Simpson JM, Kumar RK. Transesophageal echocardiography for device closure of atrial septal defects: Case selection, planning, and procedural guidance. 
JACC Cardiovasc Imag. 2009;2:1238-1242. DOI: 10.1016/j.jcmg.2009.08.003

7. Giannakoulas G, Dimopoulos K, Engel R, Goktekin O, Kucukdurmaz Z, Vatankulu $M A$, et al. Burden of coronary artery disease in adults with congenital heart disease and its relation to congenital and traditional heart risk factors. Am J Cardiol. 2009;103:1445-1450. DOI: 10.1016/j. amjcard.2009.01.353

8. Medford BA, Taggart NW, Cabalka AK, Cetta F, Reeder GS, Hagler DJ, et al. Intracardiac echocardiography during atrial septal defect and patent foramen ovale device closure in pediatric and adolescent patients. J Am Soc Echocardiogr. 2014;27:984-990. DOI: 10.1016/j.echo.2014.05.017

9. Roberson DA, Cui VW. Three-dimensional transesophageal echocardiography of atrial septal defect device closure. Curr Cardiol Rep. 2014;16:453. DOI: 10.1007/s11886013-0453-4

10. Tzifa A, Gordon J, Tibby SM, Rosenthal E, Qureshi SA. Transcatheter atrial septal defect closure guided by color flow Doppler. Int J Cardiol. 2011;149:299-303. DOI: 10.1016/j.ijcard.2010.01.014

11. Nyboe C, Hjortdal VE, Nielsen-Kudsk JE. First experiences with the GORE Septal Occluder in children and adults with atrial septal defects. Catheter Cardiovasc Interv. 2013;82:929-934. DOI: 10.1002/ ccd. 24851

12. Latson LA, Jones TK, Jacobson J, Zahn E, Rhodes JF. Analysis of factors related to successful transcatheter closure of secundum atrial septal defects using the HELEX septal occluder. Am Heart J. 2006;151:e1127e1111. DOI: 10.1016/j.ahj.2006.01.005

13. Jones TK, Latson LA, Zahn E, Fleishman $C E$, Jacobson J, Vincent R, et al. Results of the U.S. multicenter pivotal study of the HELEX septal occluder for percutaneous closure of secundum atrial septal defects. J Am Coll Cardiol. 2007;49:2215-2221. DOI: 10.1016/j.jacc.2006.11.053

14. Kazmouz S, Kenny D, Cao QL, Kavinsky CJ, Hijazi ZM.Transcatheter closure of secundum atrial septal defects. J Invasive Cardiol. 2013;25:257-264.
15. Pinto R, Jain, S, Dalvi B. Transcatheter closure of large atrial septal defects in children using the Left atrial disc engagement - disengagement technique (LADEDT) - Technical considerations and short term results. Catheter Cardiovasc Interv. 2013;82:935943. DOI: $10.1002 / \mathrm{ccd} .24873$

16. Fu YC, Cao QL, Hijazi ZM. Device closure of large atrial septal defects: Technical considerations. J Cardiovasc Med. 2007;8:30-33. DOI: 10.2459/01.JCM.0000247432.74699.47

17. Spies C, Boosefeld C, Schrader R. A modified Cook sheath for closure of a large secundum atrial septal defect. Cathet Cardiovasc Interv. 2007;70:286-289. DOI: 10.1002/ccd.21082

18. Wahab HA, Bairam AR, Cao QL, Hijazi ZM. Novel technique to prevent prolapse of the Amplatzer septal occluder through large atrial septal defect. Cathet Cardiovasc Interv. 2003;60:543-545. DOI: 10.1002/ ccd. 10686

19. Dalvi BV, Pinto RJ, Gupta A. New technique for device closure of large atrial septal defects. Cathet Cardiovasc Interv. 2005;64:102-107. DOI: 10.1002/ccd.20248

20. Kammache I, Mancini J, Ovaert C, Habib G, Fraisse A.Feasibility of transcatheter closure in unselected patients with Atrial septal defects, using Amplatzer devices and a modified sizing balloon technique. Cathet Cardiovasc Interv. 2011;78:665-674. DOI: 10.1002/ccd.23077

21. Wahab HA, Almossawy A, Al Bitar I, Hijazi ZM. Tips and tricks to prevent prolapse of the Amplatzer Septal Occluder through large atrial septal defects. Cathet Cardiovasc Interv. 2011;78:10411044. DOI: $10.1002 / c c d .23182$

22. Hill SL, Berul Cl, Patel HT, Rhodes J, Supran SE, Cao QL, et al. Early ECG abnormalities associated with transcatheter closure of atrial septal defects using the Amplatzer septal occluder. J Interv Cardiol Electrophysiol. 2000;4:469-474. DOI: 10.1023/A:1009852312907

23. Suda K, Raboisson MJ, Piette E, Dahdah NS, Miró J.Reversible atrioventricular block associated with closure of atrial septal defects using the Amplatzer device. J Am
Coll Cardiol. 2004;43:1677-1682. DOI: 10.1016/j.jacc.2003.12.042

24. Levi DS, Moore JW. Embolization and retrieval of the Amplatzer Septal Occluder. Cathet Cardiovasc Interv. 2004;61:543-547. DOI: $10.1002 / \mathrm{ccd} .20011$

25. Shirodkar S, Patil S, Pinto R, Dalvi B. Successful retrieval of migrated Amplatzer septal occluder. Ann Ped Cardiol. 2010;3:83-86. DOI: 10.4103/09742069.64365

26. Amin Z, Hijazi ZM, Bass JL, Cheatham JP, Hellenbrand WE, Kleinman CS.. Erosion of Amplatzer septal occluder device after closure of secundum atrial septal defects: review of registry of complications and recommendations to minimize future risk. Catheter Cardiovasc Interv. 2004;63:496-502. DOI: 10.1002/ccd.20211

27. Jain S, Pinto R, Dalvi B. Use of contrast during echocardiography to diagnose cardiac perforation after device closure of atrial septal defect. Catheter Cardiovasc Interv. 2014 (Epub ahead of print). DOI: $10.1002 / c c d .25373$

28. Tomar M, Khatri S, Radhakrishnan S, Shrivastava $S$. Intermediate and long-term follow up of percutaneous device closure of fossa ovalis atrial septal defect by the Amplatzer septal occluder in a cohort of 529 patients. Ann Ped Cardiol. 2011;4:22-27. DOI: 10.4103/0974-2069.79618

29. Knepp MD, Rocchini AP, Thomas R, Aiyagari RM. Long-term follow up of secundum atrial septal defect closure with the Amplatzer Septal Occluder. Congenit Heart Dis. 2010;5:32-37. DOI: 10.1111/j.17470803.2009.00358.x

Cite this article as: Jain S, Dalvi B. Atrial Septal Defect: Step-by-Step Catheter Closure. Structural Heart Disease 2016;Volume 2(1):15-32. DOI: http:// dx.doi.org/10.12945/j.jshd.2016.007.14 